University of Nebraska - Lincoln

DigitalCommons@University of Nebraska - Lincoln

Conservation of natural enemies in cotton: role of insect growth regulators in management of Bemisia tabaci

\author{
Steven E. Naranjo \\ USDA-ARS \\ Peter C. Ellsworth \\ University of Arizona \\ James R. Hagler \\ USDA-ARS
}

Follow this and additional works at: https://digitalcommons.unl.edu/usdaarsfacpub

Part of the Agricultural Science Commons

Naranjo, Steven E.; Ellsworth, Peter C.; and Hagler, James R., "Conservation of natural enemies in cotton: role of insect growth regulators in management of Bemisia tabaci" (2004). Publications from USDA-ARS / UNL Faculty. 367.

https://digitalcommons.unl.edu/usdaarsfacpub/367

This Article is brought to you for free and open access by the U.S. Department of Agriculture: Agricultural Research Service, Lincoln, Nebraska at DigitalCommons@University of Nebraska - Lincoln. It has been accepted for inclusion in Publications from USDA-ARS / UNL Faculty by an authorized administrator of DigitalCommons@University of Nebraska - Lincoln. 


\title{
Conservation of natural enemies in cotton: role of insect growth regulators in management of Bemisia tabaci ${ }^{\text {is }}$
}

\author{
Steven E. Naranjo, ${ }^{\mathrm{a}, *}$ Peter C. Ellsworth, ${ }^{\mathrm{b}}$ and James R. Hagler ${ }^{\mathrm{a}}$ \\ ${ }^{a}$ USDA-ARS, Western Cotton Research Laboratory, 4135 East Broadway Road, Phoenix, AZ 85040, USA \\ b Department of Entomology, University of Arizona, Maricopa Agricultural Center, 37860 W. Smith-Enke Road, Maricopa, AZ 85239, USA
}

Received 21 January 2003; accepted 17 September 2003

\begin{abstract}
Field studies were conducted from 1997 to 1999 to contrast the effects of two insect growth regulators (IGRs) and conventional insecticides on natural enemy conservation in cotton within the context of alternative management strategies for Bemisia tabaci (Gennadius). Compared with an untreated control, insecticide regimes based on the initial use of the IGR buprofezin or pyriproxyfen reduced densities of eight predator taxa out of 20 examined in at least one year, including common species such as Geocoris punctipes (Say), Nabis alternatus Parshley, Chrysoperla carnea s.1., and the empidid fly Drapetis nr. divergens. Patterns of predator and pest population change relative to IGR application dates suggest that factors other than direct toxic effects, such as reduction in prey availability, were likely involved. In comparison, the use of conventional insecticides reduced populations of nearly all the predatory taxa examined in most years, including those affected by IGRs, with the impact being greater and more immediate in all cases. Predator:prey ratios were significantly increased by the use of IGRs compared with both the untreated control and a conventional insecticide regime in most instances. The application of conventional insecticides for suppression of Lygus hesperus Knight, another key pest in the system, in a split-plot design reduced densities of most predator taxa and diminished the selective advantage of the IGRs. Rates of parasitism by aphelinid parasitoids (Eretmocerus eremicus Rose and Zolnerowich and Encarsia spp.) were generally low and did not vary consistently due to B. tabaci or L. hesperus insecticide regimes over the three years. Our 3year study demonstrates the more selective action of buprofezin and pyriproxyfen in an effective integrated control system for $B$. tabaci. The use of these IGRs could further facilitate biologically based management in cotton production systems.

Published by Elsevier Inc.
\end{abstract}

Keywords: Bemisia tabaci; Bemisia argentifolii; Arthropod predators; Aphelinid parasitoids; IPM; Selective insecticides; Conservation biological control; Principal response curves

\section{Introduction}

The potential of biological control to contribute to pest suppression is limited in many agricultural systems by the use of insecticides with broad toxicity to both the pest and their natural enemies (Croft, 1990). The integrated control concept formalized by Stern et al. (1959) recognizes the important contribution of both chemical and biological control to pest management in agricul-

\footnotetext{
This article presents the results of research only. Mention of a proprietary product does not constitute endorsement or recommendation for its use by USDA.

${ }^{*}$ Corresponding author. Fax: +602-437-1274.

E-mail address: snaranjo@wcrl.ars.usda.gov (S.E. Naranjo).
}

tural systems. The fundamental components of this concept involve the application of insecticides on the basis of economic thresholds and the use of selective materials, rates, and/or selective application methods that minimize impacts on natural enemy populations (Newsom et al., 1976; Stern et al., 1959).

Bemisia tabaci (Gennadius) Biotype B $(=B$. argentifolii Bellows and Perring) is a cosmopolitan pest of field and horticultural crops (Oliveira et al., 2001). Since the early 1990s, B. tabaci has been a key pest of cotton and vegetable crops in the southern US. In Arizona and southern California, large populations of B. tabaci develop during summer months in cotton leading to the extensive use of insecticides for whitefly suppression (Ellsworth and Jones, 2001; Ellsworth and MartinezCarrillo, 2001). 
Although insecticides remain the primary tactic for managing $B$. tabaci in cotton and other affected crops (Palumbo et al., 2001), considerable research has focused on the development of alternative control tactics, including the use of biological control (Gerling and Mayer, 1996; Naranjo and Ellsworth, 2001). Recent reviews have cataloged 114 species of predatory arthropods, nearly 50 species of parasitoids, and 11 species of naturally occurring fungi known to be associated with B. tabaci worldwide (Faria and Wraight, 2001; Gerling et al., 2001). In Arizona alone, over 20 species of arthropod predators prey on $B$. tabaci on cotton in the field (Hagler and Naranjo, 1994a,b, unpublished; Hagler, 2002). Several native species of Eretmocerus and Encarsia parasitize B. tabaci in Arizona and southern California (Gerling and Naranjo, 1998; Hoelmer, 1996; Naranjo et al., 2003), and many exotic aphelinid parasitoids have been introduced into the southwestern US over the past decade (Hoelmer and Kirk, 1999; Kirk and Lacey, 1996; Kirk et al., 2001). Life table studies in unsprayed cotton suggest that natural enemies, especially predators, can exert high levels of mortality on immature stages of B. tabaci (Naranjo, 2001; Naranjo and Ellsworth, unpublished). The effect of these natural enemies on populations of $B$. tabaci is not completely understood; however, several studies have documented resurgence of $B$. tabaci in cotton with use of broadspectrum insecticides (Abdelrahman and Munir, 1989; Devine et al., 1998).

Management strategies for B. tabaci on cotton in the western US are based on pest monitoring and use of action thresholds to determine the need for insecticides (Ellsworth et al., 1995, 1996b; Naranjo et al., 1998). This approach helped growers maintain profitability in the face of severe pest outbreaks in the early 1990s (Ellsworth and Jones, 2001; Ellsworth and Martinez-Carrillo, 2001). However, the broad-spectrum materials in use severely disrupted natural enemy populations (Naranjo et al., 2002), and over-reliance on these materials led to reduced susceptibility to pyrethroids in $B$. tabaci populations (Dennehy and Williams, 1997; Palumbo et al., 2001). As a result, a US-EPA Section 18 emergency exemption was granted in 1996 for two insect growth regulators (IGRs), buprofezin and pyriproxyfen. Both of these insecticides have been successfully used in Israel for suppression of $B$. tabaci in cotton and greenhouse production for many years (Ishaaya and Horowitz, 1992; Ishaaya et al., 1988) and both materials have low vertebrate toxicity and other qualities that make them relatively safe for the environment (Dhadialla et al., 1998; Pener, 2002).

Extant research on these IGRs indicate that their selectivity varies among arthropod natural enemies. The chitin inhibitor buprofezin has a relatively narrow spectrum of activity against homopterous insects, while pyriproxyfen, a juvenile hormone analog, has a broader spectrum of activity (Dhadialla et al., 1998; Ishaaya et al., 1988). Laboratory bioassay studies have found both compounds to be either benign (Balasubramani and Regupathy, 1994; Castane et al., 1996; Delbeke et al., 1997; Hoddle et al., 2001; Jones et al., 1995; Liu and Stansly, 1997; Peleg, 1988) or toxic (Chen and Liu, 2002; Declercq et al., 1995; Gerling and Sinai, 1994; Hattingh and Tate, 1995; Hoddle et al., 2001; Jones et al., 1998; Liu and Chen, 2000; Magagula and Samways, 2000; Mendel et al., 1994; Smith et al., 1999) to various predators and parasitoids. Few studies have examined the selectivity of these materials in the field (e.g., Naranjo et al., 2003).

Controlled field studies were conducted from 1997 to 1999 to contrast and demonstrate alternative management strategies for B. tabaci in Arizona. Based on pest monitoring and action thresholds, a rotation of conventional insecticides was compared with the IGRs buprofezin and pyriproxyfen. The overall project had multiple goals, including evaluation of the efficacy and economics of alternative management regimes (i.e., IGRs) for suppression of $B$. tabaci, refining action thresholds for re-application of the IGRs, evaluation of potential insecticide resistance, and measuring the effects of these alternative management regimes on natural enemy conservation. In this paper we compare the abundance of arthropod predators and aphelinid parasitoids among three different management strategies.

\section{Materials and methods}

\subsection{Study site and experimental design}

All studies were conducted at the University of Arizona, Maricopa Agricultural Center, Maricopa, AZ. Cotton, Gossypium hirsutum L. (cv. Deltapine NuCOTN 33B), was planted in early to mid-April each year, and grown according to standard agronomic practices for the area.

Similar experimental designs were used in all years and consisted of a randomized complete block, split-plot replicated four times. Whole plots consisted of one of three $B$. tabaci control regimes and an untreated control. In 1997, whole plots were $24-27$ rows wide ( $1 \mathrm{~m}$ rowspacing) by $45.7 \mathrm{~m}$ long (0.11-0.12 ha). In 1998 and 1999 whole plots measured 36 rows by $36.6 \mathrm{~m}$ long ( $0.13 \mathrm{ha}$ ). Each whole plot was split for two Lygus hesperus Knight control regimes; untreated or treated with insecticides. Split plots were 12 rows by $45.7 \mathrm{~m}$ ( 0.055 ha) in 1997 and 18 rows by $36.6 \mathrm{~m}(0.065 \mathrm{ha})$ in 1998 and 1999 . The whole plot whitefly control regimes are denoted by the initial materials used in each regime, and all applications were made on the basis of regular insect sampling and action thresholds (Table 1). In the buprofezin-first regime, the IGR buprofezin was applied at a threshold of 
Table 1

Insecticide application history, Maricopa Agricultural Center, Maricopa, AZ, 1997-1999

\begin{tabular}{|c|c|c|c|c|}
\hline \multirow[t]{2}{*}{ Date } & \multicolumn{4}{|l|}{ Main plot treatment } \\
\hline & Buprofezin $1^{\text {st }}$ & Pyriproxyfen $1^{\text {st }}$ & Conventional & Control \\
\hline \multicolumn{5}{|l|}{1997} \\
\hline 25 July & oxamyl $^{\mathrm{a}}(1121 \mathrm{~g} / \mathrm{ha})$ & oxamyl $^{\mathrm{a}}(1121 \mathrm{~g} / \mathrm{ha})$ & oxamyl $^{\mathrm{a}}(1121 \mathrm{~g} / \mathrm{ha})$ & \multirow[t]{9}{*}{ oxamyl $^{\text {a }}$ (1121 g/ha) } \\
\hline 29 July & buprofezin (392 g/ha) & pyriproxyfen (60 g/ha) & $\begin{array}{l}\text { endosulfan ( } 841 \mathrm{~g} / \mathrm{ha}) \\
+\operatorname{amitraz}(280 \mathrm{~g} / \mathrm{ha})\end{array}$ & \\
\hline 5 August & & & $\begin{array}{l}\text { oxamyl (561 g/ha) } \\
+ \text { profenophos }(841 \mathrm{~g} / \mathrm{ha})\end{array}$ & \\
\hline 13 August & \multirow[t]{2}{*}{ pyriproxyfen (60 g/ha) } & & & \\
\hline 20 August & & buprofezin (392 g/ha) & $\begin{array}{l}\text { fenpropathrin }(224 \mathrm{~g} / \mathrm{ha}) \\
+ \text { acephate }(561 \mathrm{~g} / \mathrm{ha})\end{array}$ & \\
\hline 4 September & endosulfan (841 g/ha) & endosulfan (841 g/ha) & endosulfan (841 g/ha) & \\
\hline & $+\operatorname{amitraz}(280 \mathrm{~g} / \mathrm{ha})$ & $+\operatorname{amitraz}(280 \mathrm{~g} / \mathrm{ha})$ & $+\operatorname{amitraz}(280 \mathrm{~g} / \mathrm{ha})$ & \\
\hline 12 September & oxamyl (561 g/ha) & oxamyl (561 g/ha) & fenpropathrin $(224 \mathrm{~g} / \mathrm{ha})$ & \\
\hline & + profenophos $(841 \mathrm{~g} / \mathrm{ha})$ & + profenophos $(841 \mathrm{~g} / \mathrm{ha})$ & + oxamyl $(561 \mathrm{~g} / \mathrm{ha})$ & \\
\hline \multicolumn{5}{|l|}{1998} \\
\hline 17 July & oxamyl $^{\mathrm{a}}$ (1121 g/ha) & oxamyl $^{\mathrm{a}}$ (1121 g/ha) & oxamyl $^{\mathrm{a}}$ (1121 g/ha) & oxamyl $^{\text {a }}(1121 \mathrm{~g} / \mathrm{ha})$ \\
\hline 31 July & acephate $^{\mathrm{a}}(1121 \mathrm{~g} / \mathrm{ha})$ & acephate $^{\mathrm{a}}(1121 \mathrm{~g} / \mathrm{ha})$ & acephate $^{\mathrm{a}}(1121 \mathrm{~g} / \mathrm{ha})$ & acephate $^{\mathrm{a}}(1121 \mathrm{~g} / \mathrm{ha})$ \\
\hline 6 August & buprofezin (392 g/ha) & pyriproxyfen (60 g/ha) & $\begin{array}{l}\text { endosulfan ( } 841 \mathrm{~g} / \mathrm{ha}) \\
+\operatorname{amitraz}(280 \mathrm{~g} / \mathrm{ha})\end{array}$ & \\
\hline 17 August & oxamyl $^{\text {a }}$ (1121 g/ha) & oxamyl $^{\text {a }}(1121 \mathrm{~g} / \mathrm{ha})$ & oxamyl $^{\mathrm{a}}$ (1121 g/ha) & oxamyl $^{\text {a }}$ (1121 g/ha) \\
\hline \multicolumn{5}{|l|}{1999} \\
\hline 20 July & oxamyl $^{\mathrm{a}}(1121 \mathrm{~g} / \mathrm{ha})$ & oxamyl $^{\mathrm{a}}(1121 \mathrm{~g} / \mathrm{ha})$ & oxamyl $^{\mathrm{a}}(1121 \mathrm{~g} / \mathrm{ha})$ & oxamyl $^{\mathrm{a}}(1121 \mathrm{~g} / \mathrm{ha})$ \\
\hline 29 July & acephate $^{\mathrm{a}}(1121 \mathrm{~g} / \mathrm{ha})$ & acephate $^{\mathrm{a}}(1121 \mathrm{~g} / \mathrm{ha})$ & acephate $^{\mathrm{a}}(1121 \mathrm{~g} / \mathrm{ha})$ & acephate $^{\mathrm{a}}(1121 \mathrm{~g} / \mathrm{ha})$ \\
\hline 8 August & buprofezin (392 g/ha) & pyriproxyfen (60 g/ha) & $\begin{array}{l}\text { endosulfan ( } 841 / \mathrm{ha}) \\
+\operatorname{amitraz}(280 \mathrm{~g} / \mathrm{ha})\end{array}$ & \\
\hline 13 August & oxamyl $^{\text {a }}$ (1121 g/ha) & oxamyl $^{\text {a }}$ (1121 g/ha) & oxamyl $^{\mathrm{a}}(1121 \mathrm{~g} / \mathrm{ha})$ & oxamyl $^{\text {a }}$ (1121 g/ha) \\
\hline 27 August & & & oxamyl $(561 \mathrm{~g} / \mathrm{ha})$ & \\
\hline 10 September & & & $\begin{array}{l}\text { + profenophos }(841 \mathrm{~g} / \mathrm{ha}) \\
\text { fenpropathrin }(224 \mathrm{~g} / \mathrm{ha}) \\
\text { + acephate }(561 \mathrm{~g} / \mathrm{ha})\end{array}$ & \\
\hline
\end{tabular}

All rates given in grams of active ingredient per hectare.

${ }^{a}$ Insecticides used for control of L. hesperus; applied to only one-half of the main treatment plots in a split-plot design.

one large nymphal whitefly (third or fourth instar) per leaf disk plus 3-5 adult whiteflies per leaf (see Pest Sampling below) (Ellsworth et al., 1996b). This was followed by the use of the IGR pyriproxyfen based on the same threshold, but no sooner than 2 weeks following the application of buprofezin. The pyriproxyfen-first regime consisted of the use of pyriproxyfen according to the same thresholds above with a follow-up application of buprofezin as needed, but no sooner than 3 weeks following pyriproxyfen. The waiting period between IGR uses was mandated by the US-EPA Section 18 labels in force at the time. This label also permitted only a single use of each IGR per season. If additional suppression was needed in either of these IGR regimes, a rotation of conventional insecticides was used based on a threshold of five adult whiteflies per leaf (Ellsworth et al., 1995). The conventional control regime consisted of mixtures of conventional materials rotated each time according to local resistance management guidelines and based on a threshold of five adult whiteflies per leaf (Ellsworth et al., 1995, 1996a). A final regime was left untreated for $B$. tabaci to serve as the control. In the split-plots, insecticide applications for $L$. hesperus were made on the basis of a threshold of 15 insects (adults + nymphs) per 100 sweeps. Sprays rotated between oxamyl and acephate as needed. These insecticides alone have no practical efficacy against $B$. tabaci. In 1997 only, the split-plot design was incomplete in that the "conventional" control regime was not split for $L$. hesperus control. Instead the entire whole plot was sprayed for $L$. hesperus as needed. All applications were made by tractor-mounted ground sprayers. Seasonal usage of insecticides is summarized in Table 1.

\subsection{Pest sampling}

Densities of B. tabaci eggs, nymphs, and adults were estimated each week from early July through late September or early October each year. Nymphal and egg densities were estimated by counting individuals (at $10 \times$ on a dissecting microscope) on a $3.88 \mathrm{~cm}^{2}$ disk taken from the fifth mainstem leaf below the terminal (Naranjo and Flint, 1994). Nymphs were categorized as either small (first or second instar) or large (third or 
fourth instar) for the purpose of threshold implementation (see above). Adult density was estimated by counting individuals, in situ, on the underside of leaves from the fifth mainstem node below the terminal (Naranjo and Flint, 1995). Ten sample units were randomly collected per plot for immature and adult stages on each sample date. Decisions to apply insecticides were based on the average densities in four replicate plots. Densities of $L$. hesperus were monitored weekly from early July onward using a standard $38-\mathrm{cm}$ diameter sweep net. A total of 50 sweeps were taken per plot and decisions to spray were made on the basis of counts from all treated split-plots.

\subsection{Natural enemy sampling}

Arthropod predators were sampled each week with a standard $38-\mathrm{cm}$ diameter sweep net from early June through mid to late September each year. Two sets of 25 sweeps (50 total) were collected in each plot using a random starting point. Samples were frozen and later sorted in the laboratory with the aid of a dissecting microscope. Densities of 20 taxa of arthropod predators were estimated. Immature and adult stages of most taxa were pooled for analyses. L. hesperus, Pseudatomoscelis seriatus (Reuter), Spanogonicus albofasciatus (Reuter), and Rhinacloa forticornis Reuter were included because these species may exhibit omnivorous feeding habits (Agnew et al., 1982; Butler, 1965; Hagler and Naranjo, 1994a, unpublished). Only larval stages of the green lacewing were counted, and following Tauber et al. (2000) we used the designation of Chrysoperla carnea sensu lato for this species. Voucher specimens reside in the Department of Entomology, University of Arizona, Tucson, research collection.

Predator:prey ratios were calculated as the quotient of all predators combined (per 50 sweeps) to the number of B. tabaci eggs, nymphs, adults, or all life stages per leaf combined. Egg and nymphal densities per leaf were estimated from regression models relating disk to whole leaf counts (Naranjo and Flint, 1994). Predator:prey ratios calculated for contrasts involving $L$. hesperus control excluded $L$. hesperus and $P$. seriatus, because these insects were the primary targets of control.

Densities of immature aphelinid parasitoids (Eretmocerus spp. and Encarsia spp.) were estimated by taking leaf samples (20-30 per plot) from the seventh mainstem node below the terminal. Samples were collected weekly from early July through mid to late September each year. In the laboratory all larval and pupal parasitoids of each genus (when possible) and all unparasitized fourth instar whitefly nymphs on the entire leaf were counted. The presence of visible larvae or meconia within the host mummy was used to discriminate $E n$ carsia spp. from Eretmocerus spp. after parasitoids reached later larval or pupal stages. Displacement of the host's mycetomes was used to determine the presence of young parasitoid larvae, but in these cases the genus of the parasitoid could not be discerned. An index of parasitism was calculated based on the proportion of fourth instar nymphs parasitized by both genera combined. A subsample of leaves from each plot was held to determine the species composition from emerged adults.

\subsection{Statistical analyses}

Mixed-model, repeated measures analysis of variance (Littell et al., 1996) was used to test for treatment differences over the season each year. The block variable and associated interaction terms were entered as random effects, and Satterthwaite's formula was used to estimate corrected degrees of freedom for $F$ tests. The first order heterogeneous autoregressive option (ARH1 in SAS Proc Mixed) was used to estimate the repeated measures covariance structure, as it consistently maximized Akaike's Information and Schwarz' Bayesian Criteria (Littell et al., 1996). Pre-planned orthogonal contrasts were used to compare both IGR regimes with the control and the conventional regime, to compare the conventional regime and the control, and to contrast the two IGR regimes. Treatment effects on proportional parasitism were analyzed with the SAS macro, GLIMMIX (Littell et al., 1996), which performs mixed-model ANOVA using a binomial error structure. Because the split-plot (L. hesperus control regime) design was incomplete in 1997, two sets of analyses were performed. A split-plot ANOVA was conducted after excluding the conventional regime, which was not split for $L$. hesperus control. A randomized complete block ANOVA was then conducted for all four whitefly control regimes that were treated with insecticides for control of $L$. hesperus. Arthropod counts and predator:prey ratios were transformed by $(x+0.5)^{0.5}$ or $\ln (x+1)$ throughout as necessary to achieve normality and homoscedasticity before analyses; untransformed means are presented. Analyses were limited to sample dates following the first application of insecticides for B. tabaci.

A meta-analysis was performed to summarize treatment effects over all three years. Indices were calculated as the mean of the product $p_{i} s_{i}$ over all years, where $p$ is the proportional reduction in density of each predator taxa, parasitism, or predator-prey ratio in a given insecticide regime relative to the untreated control in year $i$, and $s$ is a dummy variable indicating the statistical significance $(s=1)$ or non-significance $(s=0)$ of the reduction based on ANOVA. Additionally, mean proportional reductions (relative to the control) in predator densities, parasitism, and predator:prey ratios were calculated.

To further examine seasonal treatment effects on arthropod predator populations, a time-dependent, multivariate analysis called principal response curves (PRC) 
(van den Brink and Ter Braak, 1998, 1999) was conducted. PRC is based on an ordination method known as partial redundancy analysis, a type of principal component analysis in which information is extracted only from the variance explained by treatment effects. PRC provide a simple means of visualizing and testing the overall response of a biological community to environmental stress by determining treatment effects relative to an untreated control. The program CANOCO 4 (Ter Braak and Smilauer, 1998) was used to perform the partial redundancy analyses, construct the PRC, and test for treatment differences in community composition using a distribution-free $F$ type test based on sample permutation. In CANOCO, the analyses can be structured to account for blocking and split-plot effects and to allow statistical inference for individual dates or the entire season. Treatment contrasts similar to those for ANOVA above were performed. For analyses of $L$. hesperus control effects, we excluded $L$. hesperus and $P$. seriatus. Arthropod count data were transformed by $\ln (x+1)$ prior to analysis.

\section{Results}

In all three years, the first insecticide applications were made for control of $L$. hesperus in mid to late July (Table 1). A single application was made for this pest in 1997, but three applications were necessary in 1998 and 1999. The first insecticide applications for B. tabaci varied from late July to early August. In 1997, both IGR regimes required sprays of buprofezin and pyriproxyfen plus the application of two conventional insecticides late in the season. The conventional regime was sprayed five times over the course of the season. In 1998 and 1999 only a single application of either buprofezin or pyriproxyfen was needed in either IGR regime. In the conventional regime, one and three applications were necessary in 1998 and 1999, respectively.

\subsection{Pest populations}

Detailed analyses of treatment effects on densities of B. tabaci, yields, and overall economics are presented elsewhere (Ellsworth and Naranjo, 1999; Ellsworth et al., 1998; Ellsworth and Naranjo, unpublished data); only general results will be briefly discussed here. Population densities of B. tabaci varied over the years of the study, but were generally highest in 1997 and lowest in 1998. Densities of all B. tabaci stages were reduced in all whitefly control regimes compared with the untreated control in all years. Densities of eggs and adults were consistently lowest in the conventional regime and generally significantly higher $(P<0.05)$ in the two IGR regimes. All whitefly control regimes were equally effective in reducing densities of nymphs in all years.
The effect of $L$. hesperus control on densities of $B$. tabaci were minor; however, significant seasonal reductions $(P<0.05)$ were measured in eggs $(1999)$ and nymphs (1998 and 1999), with variable impact on adults in 1997 and 1998 .

\subsection{Predator populations and predator:prey ratios}

Many predator taxa occurred at relatively low densities over the three years of the study, especially beetles, most spiders, and several heteropterans. The most abundant spider was the crab spider, Misumenops celer (Hentz), while Orius tristicolor (White) and Geocoris punctipes (Say) were consistently the most common predaceous heteropterans. The plant pest and facultative predator $L$. hesperus consistently occurred at high densities, and P. seriatus was relatively abundant in 1997 and 1998. Larval C. carnea s.l. were relatively abundant, and adults of the empidid fly, Drapetis nr. divergens, were the most abundant predator species observed over the entire study.

There were no significant $(P>0.05)$ interactions between $B$. tabaci and L. hesperus control regimes for any taxa; thus, only main effects are presented. Sufficient numbers of immature $G$. punctipes, $O$. tristicolor, $L$. hesperus, and $P$. seriatus were available for separate analyses. However, in all cases results for immature and adult stages were similar, and so only results for adults and immatures combined are reported.

\subsubsection{7}

Based on split-plot analyses of predator densities excluding the conventional insecticide regime, seasonal average densities of five out of 19 taxa were significantly reduced $(P<0.05)$ in the IGR regimes compared with the control, including G. punctipes, Nabis alternatus Parshley, L. hesperus, C. carnea s.l., and D. nr. divergens (Table 2). No significant differences $(P>0.05)$ were detected for any taxa between the two IGR regimes. The use of insecticides for $L$. hesperus control significantly reduced $(P<0.05)$ the densities of seven predator taxa including most of those negatively affected by the IGRs (Table 2). The seasonal average density of the target, $L$. hesperus, was reduced by over $38 \%$. Predator:prey ratios were significantly higher $(P<0.05)$ in the IGR regimes compared with the control. Predator:prey ratios did not differ between the two IGR regimes, but the addition of insecticides for $L$. hesperus suppression significantly reduced $(P<0.05)$ these ratios. Predator:prey ratios varied over the season, but were consistently higher in plots not receiving additional insecticides for $L$. hesperus control (Fig. 1B).

Results from analyses based only on split-plots receiving $L$. hesperus control in 1997 were similar to those for the IGR regimes above. The exceptions were that seasonal average densities of $D$. nr. divergens in the IGR 
Table 2

Seasonal mean densities (per 50 sweeps) of arthropod predators, predator to prey ratios, and parasitism under various control regimes for $B$. tabaci and L. hesperus, Maricopa, AZ, 1997

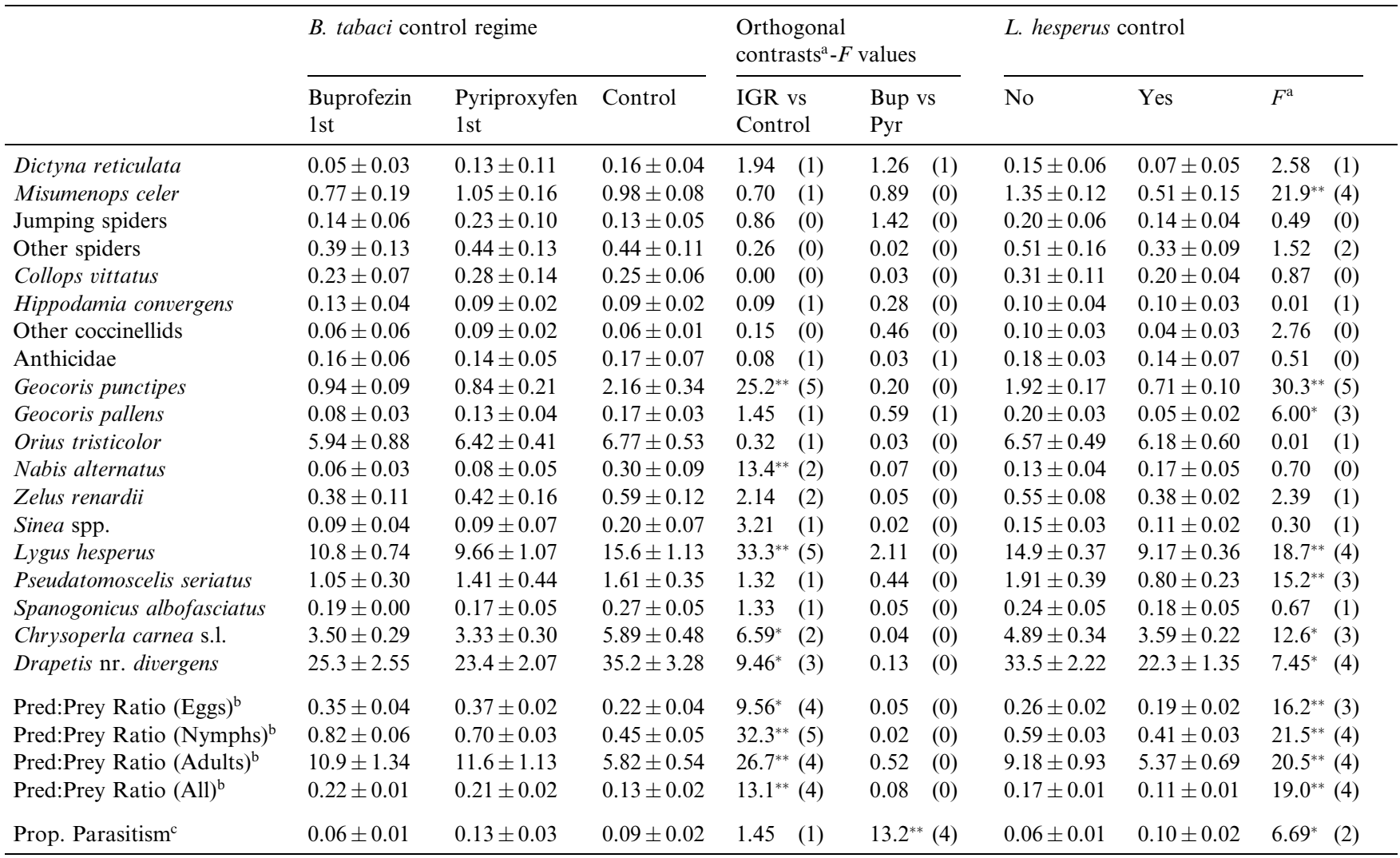

Values are mean seasonal densities \pm SE over eight post-treatment sample dates in four replicate plots $(n=4)$. Analyses do not include the conventional regime for B. tabaci control because the split-plot was incomplete for this regime (i.e., entire whole plot treated for $L$. hesperus). IGR=buprofezin + pyriproxyfen; Bup=buprofezin 1st regime; Pyr=pyriproxyfen 1st regime.

${ }^{a}$ Repeated-measures ANOVA using Proc Mixed (Littell et al., 1996); d.f. estimated by Satterthwaite's correction; ${ }^{*} P<0.05$; ${ }^{* *} P<0.01$; values in parentheses indicate the number of sample dates (out of 8 total) on which the $F$-value was significant $(P<0.05)$.

${ }^{\mathrm{b}}$ Quotient of all arthropod predators per 50 sweeps to B. tabaci eggs, nymphs, adults or all life stages combined per leaf. For $L$. hesperus control contrasts, the ratio does not include densities of $L$. hesperus or P. seriatus.

${ }^{\mathrm{c}}$ Proportion of 4 th instar B. tabaci nymphs parasitized per leaf.

regimes did not differ $(P>0.05)$ from the control (Table 3). The application of conventional insecticides had a predictable, negative effect on predator populations, significantly reducing $(P<0.05)$ densities of 12 of the 19 taxa compared with the control. Seasonal average densities of seven taxa were significantly higher $(P<0.05)$ in the IGR regimes compared with the conventional regime, including most of the spiders, and several beetles and heteropterans. Densities of Hippodamia convergens Guérin-Méneville were significantly greater $(P<0.05)$ in the buprofezin regime compared with the pyriproxyfen regime (Table 3 ). The opposite was true for the "other spiders" group.

Densities of predators varied significantly $(P<0.05)$ over time, but there were relatively few significant time interactions with either B. tabaci or $L$. hesperus control regimes (four and five taxa out of 20 , respectively). In these cases, interactions arose primarily from small changes in density differences among insecticide regimes on a few sampling dates. Usually, these changes occurred at relatively low predator densities.

Seasonal average predator:prey ratios based on $B$. tabaci nymphs and adults were significantly higher $(P<0.05)$ for the IGR regimes compared with the control and the nymph-based ratio was significantly higher for the IGR compared with the conventional regime (Table 3 ). There were no differences in any ratio between the conventional regime and the control, or between the two IGR regimes $(P>0.05)$. Predator:prey ratios varied significantly $(P<0.05)$ over time, but were generally highest in the IGR regimes and lowest in the conventional regime over most sample dates (Fig. 1A). There was a significant time by $B$. tabaci control regime interaction $(P<0.05)$ in predator:prey ratios; this was largely a function of small changes in differences between the two IGR regimes over sampling dates.

The time-dependent effect of control regimes on the predator community was further examined using 

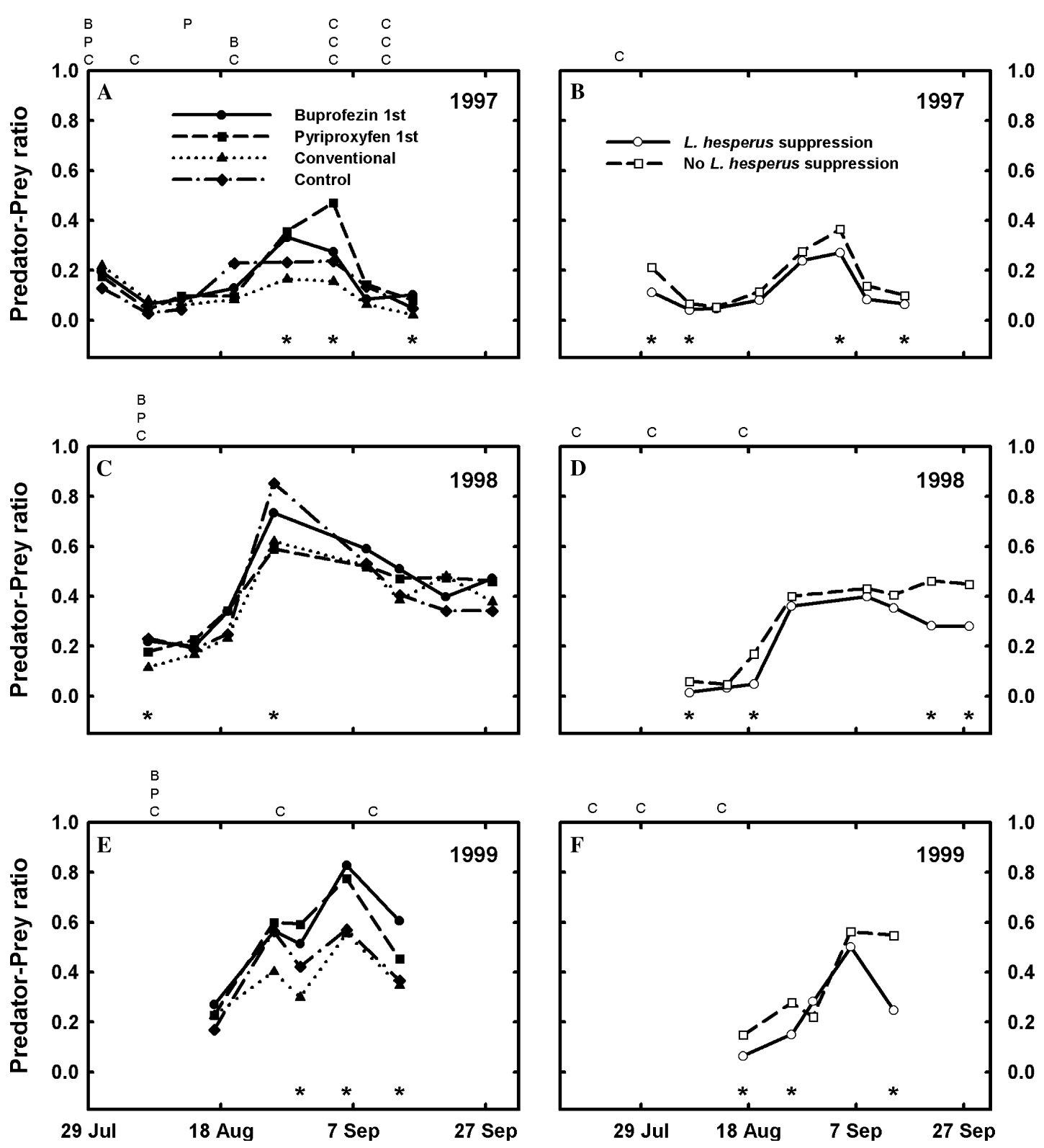

Fig. 1. The main effects of B. tabaci (A, C, E) and L. hesperus (B, D, F) control regimes on total predator to prey ratios during the growing season, 1997-1999, Maricopa, AZ. Only post-application dates for whitefly insecticides are shown. The predator-prey ratio is estimated as the quotient of all arthropod predators (per 50 sweeps) to all $B$. tabaci life stages per leaf. Asterisks along the bottom of each graph denote dates on which significant $(P<0.05)$ treatment differences were observed; letters along the top of each graph denote the timing of applications of buprofezin (B), pyriproxyfen (P) or conventional (C) insecticides. Results in A are based solely on data from split-plots receiving L. hesperus control, because the split-plot design was incomplete in 1997.

principal response curves (PRC). Results of analyses based on the split-plots receiving $L$. hesperus control are presented in Fig. 2A. The PRC based on the first axis of the redundancy analysis were highly significant $(P<0.01)$ and explained $51 \%$ of the variation due to control regime. The second axis explained an additional $12 \%$ of the variance, but was not significant $(P=0.85)$. Negative canonical coefficients indicate that populations of predators were generally lower in the insecticide regimes compared with the untreated control. Contrasts based on permutation tests over all sample dates combined indicated IGR and conventional regimes significantly reduced $(P<0.05)$ the density of the predator community compared with the untreated control. However, as with the univariate analyses, predator densities were significantly $(P<0.05)$ lower in the conventional compared with the IGR regimes. There was no difference $(P>0.05)$ between the two IGR regimes. Date by date contrasts indicate that neither IGR regime differed from the control until the last two sampling dates following the two applications of conventional insecticides (Fig. 2A). In contrast, the repeated 
Table 3

Seasonal mean densities (per 50 sweeps) of arthropod predators, predator to prey ratios, and parasitism under different control regimes for $B$. tabaci, Maricopa, AZ, 1997

\begin{tabular}{|c|c|c|c|c|c|c|c|c|c|}
\hline & B. tabaci col & trol regime & & & Orthogon & contrasts ${ }^{\mathrm{a}}-$ & values & & \\
\hline & $\begin{array}{l}\text { Buprofezin } \\
1 \text { st }\end{array}$ & $\begin{array}{l}\text { Pyriproxyfen } \\
1 \text { st }\end{array}$ & Conventional & Control & $\begin{array}{l}\text { IGR vs } \\
\text { Control }\end{array}$ & $\begin{array}{l}\text { IGR vs } \\
\text { Conven }\end{array}$ & $\begin{array}{l}\text { Conven vs } \\
\text { Control }\end{array}$ & $\begin{array}{l}\text { Bup vs } \\
\text { Pyr }\end{array}$ & \\
\hline Dictyna reticulata & $0.01 \pm 0.00$ & $0.16 \pm 0.12$ & $0.01 \pm 0.00$ & $0.06 \pm 0.04$ & 0.01 & $1.24 \quad(0)$ & $0.82 \quad(0)$ & 3.71 & (2) \\
\hline Misumenops celer & $0.41 \pm 0.09$ & $0.53 \pm 0.16$ & $0.09 \pm 0.06$ & $0.59 \pm 0.22$ & 0.97 & $6.42^{*} \quad(3)$ & $9.27^{* *}(4)$ & 0.38 & (1) \\
\hline Jumping spiders & $0.16 \pm 0.06$ & $0.19 \pm 0.11$ & $0.01 \pm 0.00$ & $0.06 \pm 0.04$ & $1.99 \quad(1)$ & $5.07^{*}(3)$ & $0.53 \quad(0)$ & 0.06 & (0) \\
\hline Other spiders & $0.16 \pm 0.09$ & $0.47 \pm 0.19$ & $0.03 \pm 0.03$ & $0.38 \pm 0.05$ & 0.60 & $5.18^{*}(2)$ & $6.98^{* *}(4)$ & $4.26^{*}$ & (1) \\
\hline Collops vittatus & $0.19 \pm 0.06$ & $0.19 \pm 0.04$ & $0.06 \pm 0.04$ & $0.22 \pm 0.03$ & 0.14 & $12.3^{* *}(4)$ & $11.0^{* *}(4)$ & 0.01 & (0) \\
\hline Hippodamia convergens & $0.16 \pm 0.03$ & $0.03 \pm 0.03$ & $0.03 \pm 0.03$ & $0.13 \pm 0.05$ & 0.42 & $1.68 \quad(0)$ & $2.84 \quad(0)$ & $5.05^{*}$ & (1) \\
\hline Other coccinellids & $0.06 \pm 0.06$ & $0.03 \pm 0.03$ & $0.03 \pm 0.03$ & $0.03 \pm 0.03$ & 0.10 & $0.10 \quad(0)$ & $0.00 \quad(0)$ & 0.29 & (0) \\
\hline Anthicidae & $0.16 \pm 0.08$ & $0.16 \pm 0.09$ & $0.06 \pm 0.06$ & $0.09 \pm 0.06$ & 1.14 & $5.67^{*}(3)$ & $0.08 \quad(0)$ & 0.01 & (0) \\
\hline Geocoris punctipes & $0.31 \pm 0.06$ & $0.56 \pm 0.26$ & $0.22 \pm 0.08$ & $1.25 \pm 0.21$ & $14.7^{* *}(3)$ & $1.09 \quad(0)$ & $17.8^{* *}(4)$ & 0.58 & (0) \\
\hline Geocoris pallens & $0.01 \pm 0.00$ & $0.06 \pm 0.04$ & $0.09 \pm 0.03$ & $0.09 \pm 0.03$ & $2.03 \quad(1)$ & $2.03 \quad(1)$ & $0.01 \quad(1)$ & 1.52 & (0) \\
\hline Orius tristicolor & $5.91 \pm 1.21$ & $6.03 \pm 0.69$ & $2.63 \pm 0.58$ & $6.59 \pm 1.02$ & 0.06 & $16.2^{* *}(5)$ & $13.7^{* *}(4)$ & 0.01 & (0) \\
\hline Nabis alternatus & $0.09 \pm 0.03$ & $0.09 \pm 0.06$ & $0.06 \pm 0.06$ & $0.31 \pm 0.11$ & $6.40^{*}(2)$ & $0.31 \quad(0)$ & $7.15^{*} \quad(3)$ & 0.01 & (0) \\
\hline Zelus renardii & $0.25 \pm 0.11$ & $0.31 \pm 0.23$ & $0.06 \pm 0.06$ & $0.56 \pm 0.13$ & $2.71 \quad(0)$ & $1.40 \quad(1)$ & $6.00^{*} \quad(3)$ & 0.09 & (0) \\
\hline Sinea spp. & $0.03 \pm 0.03$ & $0.13 \pm 0.09$ & $0.01 \pm 0.00$ & $0.19 \pm 0.06$ & $2.33 \quad(0)$ & $1.21 \quad(1)$ & $5.18^{*}(2)$ & 1.02 & (0) \\
\hline Lygus hesperus & $8.09 \pm 0.89$ & $6.78 \pm 1.16$ & $4.13 \pm 0.55$ & $12.6 \pm 0.92$ & $26.6^{* *}(2)$ & $15.1^{* *}(4)$ & $61.3^{* *}(6)$ & 0.86 & (0) \\
\hline Pseudatomoscelis seriatus & $0.47 \pm 0.34$ & $0.75 \pm 0.42$ & $0.22 \pm 0.08$ & $1.19 \pm 0.36$ & $2.49 \quad(1)$ & $1.49 \quad(2)$ & $5.88^{*}(2)$ & 0.59 & (0) \\
\hline Spanogonicus albofasciatus & $0.19 \pm 0.04$ & $0.19 \pm 0.11$ & $0.06 \pm 0.04$ & $0.16 \pm 0.06$ & 0.20 & 2.16 & $0.79 \quad(0)$ & 0.01 & (0) \\
\hline Chrysoperla carnea s.l. & $3.03 \pm 0.48$ & $2.41 \pm 0.24$ & $3.28 \pm 0.59$ & $5.34 \pm 0.79$ & $7.81^{*} \quad(3)$ & 0.01 & $5.37^{*}(3)$ & 0.44 & (0) \\
\hline Drapetis nr. divergens & $19.6 \pm 3.27$ & $22.1 \pm 2.23$ & $15.8 \pm 3.78$ & $25.1 \pm 3.50$ & $1.45 \quad(0)$ & $1.51 \quad(1)$ & $4.89^{*}(1)$ & $0.43 \quad(C$ & (0) \\
\hline Pred:Prey Ratio (Eggs) ${ }^{\mathrm{b}}$ & $0.29 \pm 0.06$ & $0.29 \pm 0.04$ & $0.22 \pm 0.04$ & $0.18 \pm 0.03$ & $2.43 \quad(2)$ & $0.17 \quad(1)$ & 0.98 & 0.06 & (0) \\
\hline Pred:Prey Ratio (Nymphs) ${ }^{\mathrm{b}}$ & $0.60 \pm 0.10$ & $0.61 \pm 0.03$ & $0.36 \pm 0.05$ & $0.34 \pm 0.02$ & $11.2^{* *}(4)$ & $9.59^{* *}(3)$ & 0.04 & 0.30 & (0) \\
\hline Pred:Prey Ratio (Adults) ${ }^{\mathrm{b}}$ & $7.75 \pm 2.02$ & $8.25 \pm 0.71$ & $7.26 \pm 0.80$ & $4.79 \pm 0.41$ & $5.03^{*}(3)$ & $0.41 \quad(1)$ & 1.89 & 0.40 & (0) \\
\hline Pred:Prey Ratio (All) ${ }^{\mathrm{b}}$ & $0.16 \pm 0.03$ & $0.18 \pm 0.02$ & $0.13 \pm 0.02$ & $0.11 \pm 0.02$ & $3.45 \quad(2)$ & 0.82 & 0.67 & 0.01 & (0) \\
\hline Prop. Parasitism ${ }^{\mathrm{c}}$ & $0.05 \pm 0.01$ & $0.11 \pm 0.04$ & $0.04 \pm 0.01$ & $0.06 \pm 0.02$ & 1.70 & $1.41 \quad(1)$ & $0.01 \quad(0)$ & $5.46^{*}($ & (2) \\
\hline
\end{tabular}

Values are mean seasonal densities \pm SE over eight post-treatment sample dates in four replicate plots $(n=4)$. Analyses based only on split plots receiving $L$. hesperus control. IGR=buprofezin + pyriproxyfen; Bup=buprofezin 1st regime; Pyr=pyriproxyfen 1st regime; Conven=conventional whitefly control regime.

${ }^{a}$ Repeated-measures ANOVA using Proc Mixed (Littell et al., 1996); d.f. estimated by Satterthwaite's correction; ${ }^{*} P<0.05 ;{ }^{* *} P<0.01$; values in parentheses indicate the number of sample dates (out of 8 total) on which the $F$-value was significant $(P<0.05)$.

${ }^{\mathrm{b}}$ Quotient of all arthropod predators per 50 sweeps to $B$. tabaci eggs, nymphs, adults or all life stages combined per leaf

${ }^{\mathrm{c}}$ Proportion of 4 th instar B. tabaci nymphs parasitized per leaf.

application of insecticides in the conventional regime depressed predator densities on multiple dates throughout the growing season and these reductions followed the pattern of application. A single application of oxamyl for $L$. hesperus in late July resulted in a large initial reduction in predator populations (Fig. 2B). Populations rebounded in early to mid-August but were significantly lower compared with the untreated control in late August and early September. The PRC based on the first axis of the redundancy analysis was highly significant $(P<0.01)$ and explained $71 \%$ of the variation. The second axis explained an additional $9 \%$, but was not significant $(P=0.75)$.

The species weights denote the strength of the response for each individual taxa (Fig. 2). The higher the value the more the response of a given taxa resembles the PRC. Negative weights indicate an opposite pattern and values between -0.5 and 0.5 indicate a weak response or a response unrelated to the PRC (van den Brink and Ter Braak, 1999). Species weights suggest that the PRC for the both the B. tabaci and L. hesperus control regimes are most representative of $L$. hesperus, $O$. tristicolor, G. punctipes, C. carnea s.1., P. seriatus, D. nr. divergens, $M$. celer, Zelus renardii Kolenati, and the "other spider" group.

\subsubsection{8}

Seasonal average densities of only $D$. nr. divergens and $S$. albofasciatus were significantly reduced $(P<0.05)$ in the IGR regimes compared with the control, while densities of the "other spider" group increased significantly in the IGR regimes (Table 4). In contrast, densities of 11 taxa were significantly reduced $(P<0.05)$ in the conventional regime compared with the control. For 10 predator taxa, densities were significantly higher $(P<0.05)$ in the IGR compared with the conventional regime (Table 4$)$. There were no significant differences $(P>0.05)$ between the two IGR regimes for any predator taxa. Insecticides for control of $L$. hesperus significantly reduced $(P<0.05)$ seasonal average densities of 16 predator taxa (Table 4$)$. The seasonal average density of the target, $L$. hesperus, was reduced by over $52 \%$. 

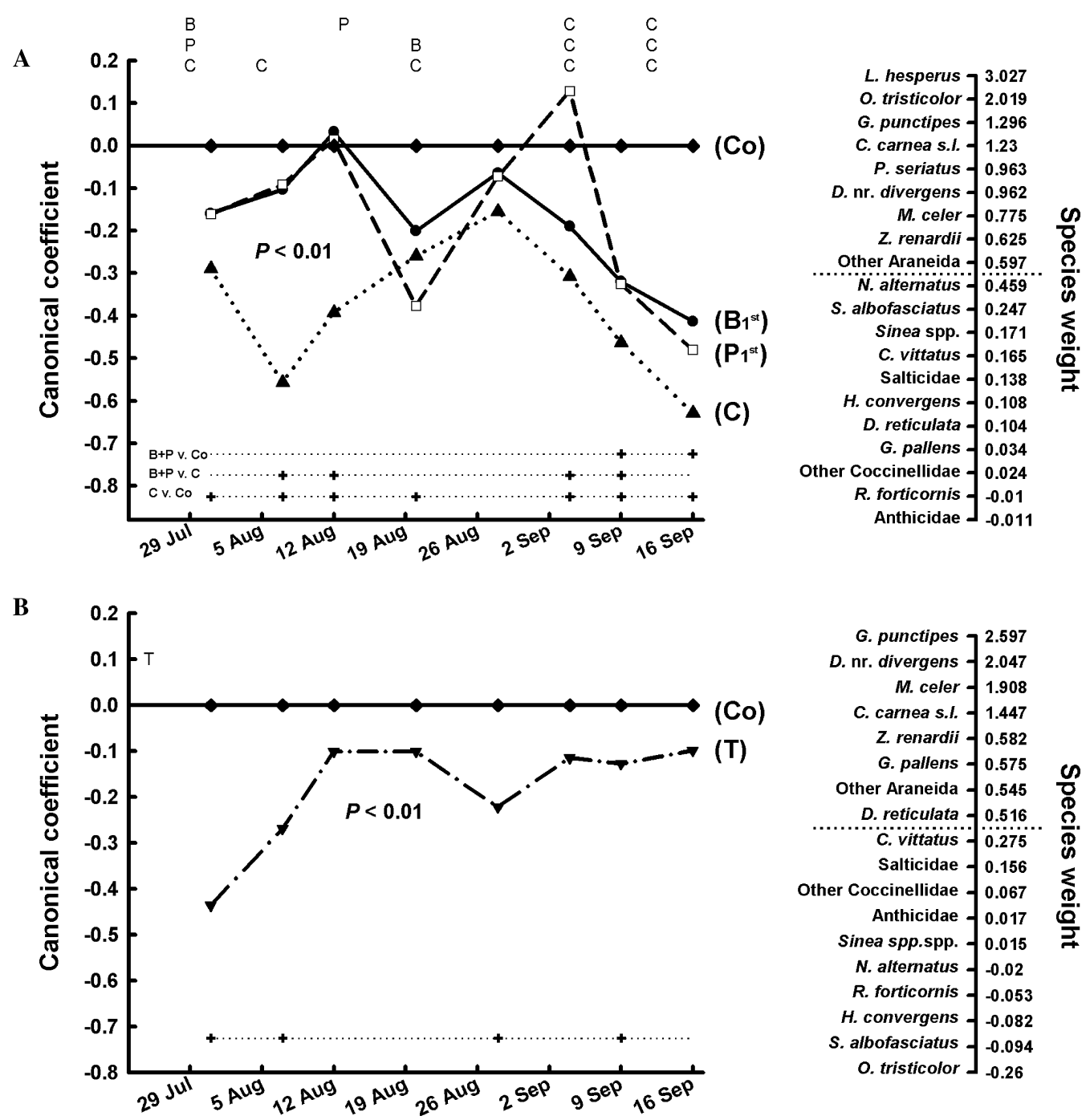

Fig. 2. Principal response curves (PRC) showing the main effects of (A) whitefly control (only post-application dates for whitefly insecticides are shown), and (B) L. hesperus control (only post-application dates for L. hesperus insecticides are shown) on the predatory arthropod community during the growing season, 1997, Maricopa, AZ. The PRC show the effect of each treatment regime relative to the untreated control (Co) which is represented by the $y=0$ line. The greater the species weight the more the response for that species resembles the PRC. Negative weights indicate an opposite pattern, and weights between -0.5 and 0.5 indicate a weak response or a response unrelated to the PRC. The $P$-value denotes the significance of the PRC analysis over all dates based on an $F$-type permutation test. The plus symbols at the base of each graph denote the significance $(P<0.05)$ of the indicated contrast on each date determined by $F$-type permutation test; letters along the top of each graph denote the timing of applications of buprofezin (B), pyriproxyfen $(\mathrm{P})$, or conventional insecticides for whitefly $(\mathrm{C})$ or $L$. hesperus $(\mathrm{T})$. There were no significant differences between the two IGRs on any date and so contrasts are not shown. Results in A are based solely on data from split-plots receiving $L$. hesperus control, because the split-plot design was incomplete in 1997.

Most predator densities varied significantly $(P<0.05)$ over time and significant time by $B$. tabaci control regime interactions were observed for $D$. nr. divergens and $L$. hesperus. These interactions arose from small differences in insecticide effects on two or three sampling dates. Significant time by $L$. hesperus control interactions were detected for seven taxa and this was primarily due to small changes in insecticide effects on one or two sampling dates.

Predator:prey ratios based on $B$. tabaci adults were significantly higher $(P<0.05)$ in the IGR and conventional regimes compared with the control and ratios based on nymphs were significantly higher $(P<0.05)$ in the IGR compared with the conventional regime (Table 4). Predator:prey ratios based on all B. tabaci stages combined varied significantly $(P<0.05)$ over time (Fig. 1C). Significant treatment differences were only observed during the first four sample dates following insecticide application; however, ratios were numerically lowest in the conventional regime over a large portion of the season. Predator:prey ratios based on eggs, nymphs and all stages combined were significantly reduced $(P<0.05)$ with the addition of insecticides for $L$. hesperus control (Table 4, Fig. 1D). There 
Table 4

Seasonal mean densities (per 50 sweeps) of arthropod predators, predator to prey ratios, and parasitism under various control regimes for B. tabaci and L. hesperus, Maricopa, AZ, 1998

\begin{tabular}{|c|c|c|c|c|c|c|c|c|c|c|c|}
\hline \multirow[b]{3}{*}{ Dictyna reticulata } & \multicolumn{4}{|c|}{ B. tabaci control regime } & \multicolumn{4}{|c|}{ Orthogonal contrasts ${ }^{\mathrm{a}}-F$ values } & \multicolumn{3}{|c|}{ L. hesperus control } \\
\hline & \multirow{2}{*}{$\begin{array}{l}\begin{array}{l}\text { Buprofezin } \\
1^{\text {st }}\end{array} \\
0.42 \pm 0.06\end{array}$} & \multirow{2}{*}{$\begin{array}{l}\text { Pyriproxyfen } \\
1^{\text {st }} \\
0.38 \pm 0.05\end{array}$} & \multirow{2}{*}{$\begin{array}{l}\text { Conven } \\
0.33 \pm 0.10\end{array}$} & \multirow{2}{*}{$\begin{array}{l}\text { Control } \\
0.50 \pm 0.11\end{array}$} & $\begin{array}{l}\text { IGR vs } \\
\text { Control }\end{array}$ & $\begin{array}{l}\text { IGR vs } \\
\text { Conven }\end{array}$ & $\begin{array}{l}\text { Conven vs } \\
\text { Control }\end{array}$ & \multirow{2}{*}{$\begin{array}{l}\text { Bup vs } \\
\text { Pyr } \\
0.28(0)\end{array}$} & \multirow{2}{*}{$\begin{array}{l}\text { No } \\
0.56 \pm 0.02\end{array}$} & \multirow{2}{*}{$\begin{array}{l}\text { Yes } \\
0.25 \pm 0.07\end{array}$} & \multirow{2}{*}{$\begin{array}{l}F^{\mathrm{a}} \\
7.33^{*} \text { (3) }\end{array}$} \\
\hline & & & & & $0.03 \quad(0)$ & $0.89 \quad(0)$ & $0.92 \quad(0)$ & & & & \\
\hline Misumenops celer & $8.79 \pm 0.76$ & $8.59 \pm 0.22$ & $6.58 \pm 0.32$ & $7.67 \pm 0.32$ & $2.10 \quad(1)$ & $15.5^{*}(4)$ & $4.63^{*}(3)$ & $0.02(0)$ & $10.5 \pm 0.54$ & $5.34 \pm 0.24$ & $116^{* *}(7)$ \\
\hline Jumping spiders & $1.70 \pm 0.23$ & $1.79 \pm 0.14$ & $1.50 \pm 0.26$ & $1.72 \pm 0.14$ & $0.02 \quad(1)$ & $1.20 \quad(0)$ & $0.66 \quad(2)$ & $0.02(0)$ & $1.98 \pm 0.15$ & $1.37 \pm 0.08$ & $10.4^{* *}(3)$ \\
\hline Other spiders & $1.95 \pm 0.29$ & $1.77 \pm 0.34$ & $1.70 \pm 0.17$ & $1.20 \pm 0.27$ & $5.35^{*}(1)$ & $1.36 \quad(0)$ & $0.99 \quad(0)$ & $0.66(0)$ & $2.02 \pm 0.28$ & $1.29 \pm 0.34$ & $11.3^{* *}(3)$ \\
\hline Collops vittatus & $0.39 \pm 0.08$ & $0.26 \pm 0.04$ & $0.16 \pm 0.05$ & $0.48 \pm 0.06$ & $2.54 \quad(1)$ & $6.22 *(2)$ & $13.1^{* *}(3)$ & $2.40(1)$ & $0.36 \pm 0.06$ & $0.29 \pm 0.05$ & 1.51 \\
\hline Hippodamia convergens & $0.19 \pm 0.03$ & $0.23 \pm 0.09$ & $0.09 \pm 0.06$ & $0.20 \pm 0.09$ & $0.35 \quad(1)$ & $3.80 \quad(0)$ & $1.37 \quad(2)$ & $0.45(0)$ & $0.27 \pm 0.04$ & $0.09 \pm 0.03$ & $9.8^{*} \quad(3)$ \\
\hline Other coccinellids & $0.05 \pm 0.04$ & $0.11 \pm 0.05$ & $0.11 \pm 0.09$ & $0.13 \pm 0.05$ & $0.27 \quad(0)$ & 0.05 & $0.37 \quad(0)$ & $0.37(1)$ & $0.19 \pm 0.10$ & $0.01 \pm 0.01$ & $4.58^{*}(2)$ \\
\hline Anthicidae & $0.41 \pm 0.23$ & $0.66 \pm 0.29$ & $0.11 \pm 0.03$ & $0.47 \pm 0.20$ & $0.09 \quad(1)$ & $5.40^{*}(3)$ & $4.70^{*}(1)$ & $1.41(1)$ & $0.41 \pm 0.04$ & $0.41 \pm 0.02$ & $0.40 \quad(0)$ \\
\hline Geocoris punctipes & $1.34 \pm 0.32$ & $1.32 \pm 0.22$ & $0.83 \pm 0.18$ & $1.39 \pm 0.13$ & $0.05 \quad(0)$ & $7.60^{* *}(2)$ & $4.77^{*}(2)$ & $0.00(0)$ & $1.91 \pm 0.24$ & $0.53 \pm 0.07$ & $59.2^{* *}(6)$ \\
\hline Geocoris pallens & $0.41 \pm 0.04$ & $0.48 \pm 0.10$ & $0.17 \pm 0.05$ & $0.48 \pm 0.03$ & $0.01 \quad(1)$ & $9.38^{* *}(3)$ & $6.65^{*}(3)$ & $0.43(1)$ & $0.48 \pm 0.06$ & $0.29 \pm 0.03$ & $4.47^{*}(3)$ \\
\hline Orius tristicolor & $6.13 \pm 0.39$ & $4.87 \pm 0.21$ & $5.09 \pm 0.47$ & $7.09 \pm 0.49$ & $3.46 \quad(1)$ & $1.10 \quad(0)$ & $6.37^{*}(2)$ & $2.45(0)$ & $6.25 \pm 0.49$ & $5.35 \pm 0.49$ & $6.25^{*}$ \\
\hline Nabis alternatus & $0.16 \pm 0.02$ & $0.13 \pm 0.03$ & $0.06 \pm 0.01$ & $0.14 \pm 0.05$ & $0.01 \quad(0)$ & $5.26^{*}(2)$ & $2.27 \quad(1)$ & $0.13(0)$ & $0.16 \pm 0.02$ & $0.08 \pm 0.01$ & $5.48^{*}(2)$ \\
\hline Zelus renardii & $3.18 \pm 0.20$ & $2.94 \pm 0.37$ & $2.73 \pm 0.22$ & $3.25 \pm 0.35$ & $0.84 \quad(1)$ & $1.38 \quad(1)$ & 3.27 & $0.24(0)$ & $3.92 \pm 0.15$ & $2.13 \pm 0.17$ & $87.3^{* *}(6)$ \\
\hline Sinea spp. & $0.23 \pm 0.07$ & $0.23 \pm 0.05$ & $0.28 \pm 0.13$ & $0.14 \pm 0.07$ & $1.42 \quad(0)$ & $0.02 \quad(0)$ & $0.85 \quad(0)$ & $0.00(0)$ & $0.27 \pm 0.07$ & $0.18 \pm 0.07$ & $0.96 \quad(0)$ \\
\hline Lygus hesperus & $24.7 \pm 1.09$ & $24.5 \pm 1.38$ & $20.1 \pm 1.17$ & $24.0 \pm 1.47$ & $0.00 \quad(0)$ & $19.9^{* *}(4)$ & $15.2^{* *}(5)$ & $0.18(0)$ & $31.6 \pm 1.52$ & $15.0 \pm 0.78$ & $128^{* *}(6)$ \\
\hline Pseudatomoscelis seriatus & $1.41 \pm 0.08$ & $1.28 \pm 0.20$ & $0.73 \pm 0.26$ & $1.56 \pm 0.12$ & $0.10 \quad(0)$ & $9.21^{* *}(3)$ & $8.41^{* *}(3)$ & $0.59(0)$ & $1.78 \pm 0.05$ & $0.71 \pm 0.12$ & $32.4^{* *}(6)$ \\
\hline Spanogonicus albofasciatus & $0.16 \pm 0.04$ & $0.11 \pm 0.02$ & $0.09 \pm 0.02$ & $0.36 \pm 0.12$ & $7.12^{*}(1)$ & $0.62 \quad(0)$ & $8.94^{* *}(2)$ & $0.58(0)$ & $0.18 \pm 0.03$ & $0.18 \pm 0.03$ & $0.00 \quad(0)$ \\
\hline Rhinacloa forticornis & $0.66 \pm 0.12$ & $0.55 \pm 0.12$ & $0.55 \pm 0.19$ & $0.78 \pm 0.22$ & $1.07 \quad(0)$ & 0.39 & $0.42 \quad(0)$ & $0.39(0)$ & $0.91 \pm 0.18$ & $0.36 \pm 0.13$ & $17.2^{* *}(4)$ \\
\hline Chrysoperla carnea s.l. & $1.78 \pm 0.12$ & $1.56 \pm 0.11$ & $1.46 \pm 0.17$ & $1.88 \pm 0.27$ & $0.01 \quad(0)$ & $5.33^{*}(2)$ & $4.08^{*}(1)$ & $0.06(0)$ & $2.16 \pm 0.09$ & $1.17 \pm 0.10$ & $27.1^{* *}(5)$ \\
\hline Drapetis nr. divergens & $8.00 \pm 1.45$ & $6.21 \pm 1.64$ & $6.27 \pm 0.76$ & $13.2 \pm 5.64$ & $5.58^{*}(1)$ & $5.91^{*}(3)$ & $14.9^{* *}(4)$ & $4.86(2)$ & $11.3 \pm 3.26$ & $5.57 \pm 1.47$ & $28.1^{* *}(6)$ \\
\hline Pred:Prey Ratio (Eggs) ${ }^{\mathrm{b}}$ & $0.84 \pm 0.07$ & $0.77 \pm 0.07$ & $0.93 \pm 0.04$ & $0.76 \pm 0.07$ & $1.66 \quad(1)$ & 0.69 & 3.38 & $0.91(1)$ & $0.61 \pm 0.04$ & $0.45 \pm 0.06$ & $26.7^{* *}(4)$ \\
\hline Pred:Prey Ratio (Nymphs) ${ }^{\mathrm{b}}$ & $1.07 \pm 0.07$ & $1.06 \pm 0.07$ & $0.96 \pm 0.03$ & $0.98 \pm 0.08$ & $2.39 \quad(1)$ & $7.22^{*}(4)$ & 1.09 & $0.05(0)$ & $0.70 \pm 0.06$ & $0.49 \pm 0.05$ & $46.9^{* *}(5)$ \\
\hline Pred:Prey Ratio (Adults) & $19.9 \pm 1.24$ & $22.6 \pm 1.24$ & $23.4 \pm 0.63$ & $15.0 \pm 2.85$ & $15.7^{* *}(3)$ & $1.02 \quad(4)$ & $18.3^{* *}(4)$ & $1.82(1)$ & $12.9 \pm 0.44$ & $11.7 \pm 1.42$ & $1.09 \quad(2)$ \\
\hline Pred:Prey Ratio (All) ${ }^{\mathrm{b}}$ & $0.43 \pm 0.03$ & $0.41 \pm 0.03$ & $0.44 \pm 0.02$ & $0.39 \pm 0.03$ & 1.81 & 0.24 & $0.55 \quad(2)$ & $0.46(0)$ & $0.30 \pm 0.02$ & $0.22 \pm 0.03$ & $35.1^{* *}(4)$ \\
\hline Prop. parasitism ${ }^{\mathrm{c}}$ & $0.13 \pm 0.02$ & $0.12 \pm 0.02$ & $0.14 \pm 0.02$ & $0.14 \pm 0.02$ & $0.02 \quad(0)$ & $0.11 \quad(0)$ & $0.16 \quad(1)$ & $2.13(2)$ & $0.16 \pm 0.02$ & $0.11 \pm 0.01$ & $6.41^{*}$ \\
\hline
\end{tabular}

Values are mean seasonal densities \pm SE over eight post-treatment sample dates in four replicate plots $(n=4)$. IGR=buprofezin + pyriproxyfen; Bup=buprofezin 1 st regime; Pyr=pyriproxyfen 1st regime; Conven=conventional whitefly control regime.

${ }^{\text {a }}$ Repeated-measures ANOVA using Proc Mixed (Littell et al., 1996); d.f. estimated by Satterthwaite's correction; ${ }^{*} P<0.05$; ${ }^{* *} P<0.01$; values in parentheses indicate the number of sample dates (out of 8 total) on which the $F$-value was significant $(P<0.05)$

${ }^{\mathrm{b}}$ Quotient of all arthropod predators per 50 sweeps to B. tabaci eggs, nymphs, adults or all life stages combined per leaf. For $L$. hesperus control contrasts, the ratio does not include densities of L. hesperus or P. seriatus.

${ }^{c}$ Proportion of 4 th instar B. tabaci nymphs parasitized per leaf. 
were significant $(P<0.05)$ time by $B$. tabaci control regime interactions. This was largely due to inconsistent treatment effects over time, especially among the IGR regimes and the untreated control (Fig. 1C). The effect of $L$. hesperus control on predator:prey ratios was consistent and no interaction with time was detected $(P>0.05)$.

PRC for B. tabaci control regimes based on the first axis of the redundancy analysis were significant $(P<0.01)$ and explained $38 \%$ of the variation due to treatment regime (Fig. 3A). The second axis explained an additional $13 \%$ of the variance, but was not significant $(P=0.41)$. Contrasts based on permutation tests for all sample dates combined indicated that the conventional, but not the IGR regimes, significantly reduced $(P<0.05)$ the overall density of predators compared with the untreated control. Predator densities also were significantly lower $(P<0.05)$ in conventional compared with the IGR regimes. There was no difference $(P>0.05)$ between the two IGR regimes. Date by date contrasts indicated that the IGR regimes differed from the control on a singe date in early September well after insecticide applications. In contrast, a single application of conventional insecticides in early August initially reduced predator densities for two weeks
A

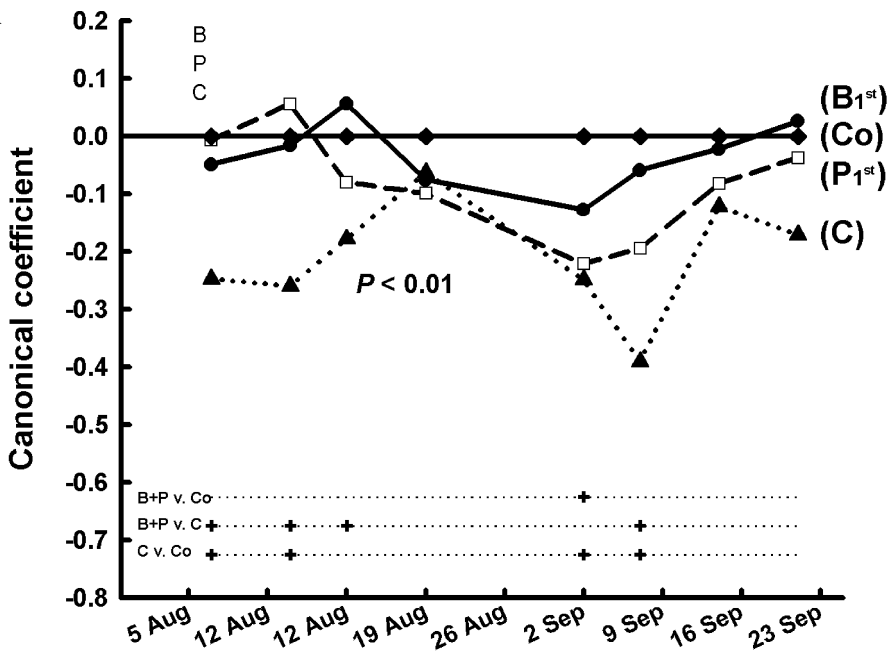

B

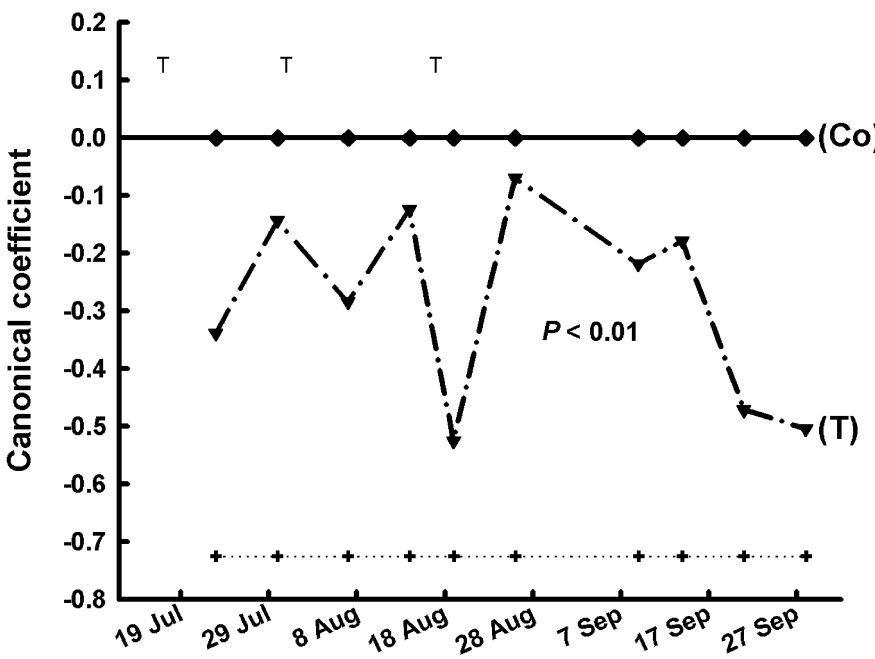

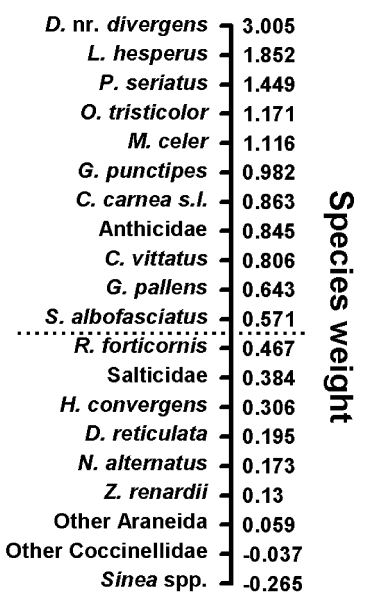

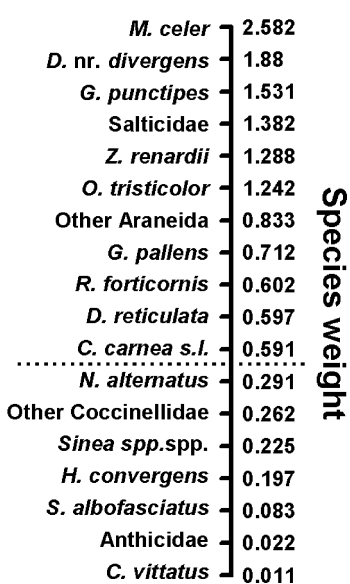

Fig. 3. Principal response curves (PRC) showing the main effects of (A) whitefly control (only post-application dates for whitefly insecticides are shown), and (B) L. hesperus control (only post-application dates for L. hesperus insecticides are shown) on the predatory arthropod community during the growing season, 1998, Maricopa, AZ. The PRC show the effect of each treatment regime relative to the untreated control (Co) which is represented by the $y=0$ line. The greater the species weight the more the response for that species resembles the PRC. Negative weights indicate an opposite pattern and weights between -0.5 and 0.5 indicate a weak response or a response unrelated to the PRC. The $P$-value denotes the significance of the PRC analysis over all dates based on an $F$-type permutation test. The plus symbols at the base of each graph denote the significance $(P<0.05)$ of the indicated contrast on each date determined by $F$-type permutation test; letters along the top of each graph denote the timing of applications of buprofezin (B), pyriproxyfen (P), or conventional insecticides for whitefly $(\mathrm{C})$ or L. hesperus $(\mathrm{T})$. There were no significant differences between the two IGRs on any date and so contrasts are not shown. 
following the spray and led to significant reductions $(P<0.05)$ from early to mid-September. Species weights indicate that the PRC were representative of 11 out of 20 taxa with the highest weights associated with $D$. nr. divergens, L. hesperus, $P$. seriatus, $O$. tristicolor, $M$. celer, and G. punctipes (Fig. 3A). Repeated applications of conventional insecticides for control of $L$. hesperus had a strong negative effect on predator populations throughout the entire season with marked reductions following each of the three applications in mid to late July and mid-August (Fig. 3B). The PRC based on the first axis of the redundancy analysis was highly significant $(P<0.01)$ and explained $68 \%$ of the variation due to insecticide application for $L$. hesperus. The second axis explained an additional $13 \%$, but was not significant $(P=0.18)$. Species weights indicate that the PRC were representative of 11 out of 18 taxa with the highest weights associated with $M$. celer, D. nr. divergens, $G$. punctipes, salticid spiders, $Z$. renardii and $O$. tristicolor (Fig. 3B).

\subsubsection{9}

Seasonal average densities of four out of 19 predator taxa were significantly reduced $(P<0.05)$ in the IGR regimes compared with the control including $M$. celer, other coccinellids, $C$. carnea s.l. and $D$. nr. divergens (Table 5). In contrast, densities of nine predator taxa were significantly reduced $(P<0.05)$ in the conventional regime compared with the control (Table 5). Seasonal average densities of 10 predator taxa were significantly higher $(P<0.05)$ in the IGR compared with the conventional regime (Table 5). There were no significant $(P>0.05)$ differences between the two IGR regimes for any predator taxa. L. hesperus control significantly $(P<0.05)$ reduced the densities of 12 predator taxa (Table 5). The seasonal average density of the target, $L$. hesperus, was reduced by about $52 \%$.

Predator densities varied significantly $(P<0.05)$ over the growing season, and significant time by $B$. tabaci control regime interactions were observed for six taxa. In most cases these interactions resulted from inconsistent treatment effects that occurred at relatively low densities. Significant time by $L$. hesperus control interactions were detected for $O$. tristicolor and $D$. nr. divergens. For the former, the interaction arose due to an increase in density in the sprayed regime on a single date in early September. For D. nr. divergens reductions in density in the sprayed plots were magnified on the last two sampling dates.

All predator:prey ratios were significantly higher $(P<0.05)$ in the IGR compared with the control, and ratios based on nymphs and all stages combined were significantly higher $(P<0.05)$ in IGR compared with the conventional regime (Table 5). The nymphal-based ratio was higher in the control compared with the conventional regime; all ratios were similar between the
IGR regimes. Predator:prey ratios varied over time, and significant treatment differences $(P<0.05)$ were observed on the final three sampling dates (Fig. 1E.). Ratios were generally higher in IGR and lowest in conventional regimes over most of the growing season. Predator:prey ratios based on eggs, nymphs, and on all stages combined were significantly reduced $(P<0.05)$ with the addition of insecticides for $L$. hesperus control, and this pattern was generally consistent over the season (Table 5, Fig. 1F). There were significant $(P<0.05)$ time by $B$. tabaci control regime interactions resulting primarily from the variable effects between the two IGR regimes and the inconsistent pattern in the control relative to the conventional regime (Fig. 1E). There was a significant $(P<0.05)$ time by $L$. hesperus control interaction that was due mainly to the response in the untreated control on the third sampling date (Fig. 1F).

PRC for the $B$. tabaci control regime based on the first axis of the redundancy analysis were highly significant $(P<0.01)$ and explained $51 \%$ of the variation due to treatment regime. The second axis explained an additional $12 \%$ of the variance, but was not significant $(P=0.27)$. Contrasts based on permutation tests for all sample dates combined indicated that both the IGR and conventional regimes significantly reduced $(P<0.05)$ the overall density of the predator community compared with the untreated control (Fig. 4A). However, again, reductions in predator density were significantly greater $(P<0.05)$ in the conventional compared with the IGR regimes. There was no difference $(P>0.05)$ between the two IGR regimes. Date by date contrasts showed that the IGR regimes differed from the control on two sample dates towards the latter part of the growing season many weeks following insecticide applications (Fig. 4A). In the conventional regime significant reductions in predator densities were associated with each of the three insecticide applications. Species weights indicate that the PRC were most representative of $M$. celer, G. punctipes, $L$. hesperus, O. tristicolor, D. nr. divergens, C. carnea s.1., other coccinellids and spiders, and Collops vittatus Say (Fig. 4A). Repeated applications of insecticides for control of $L$. hesperus negatively affected predator populations throughout the entire season with marked reductions following each application (Fig. 4B). PRC based on the first axis of the redundancy analysis was highly significant $(P<0.01)$ and explained $76 \%$ of the variation. The second axis explained an additional 14\%, but again, was not significant $(P=0.15)$. Species weights indicate that the PRC was most representative of $D$. nr. divergens, O. tristicolor, G. punctipes, M. celer, C. carnea s.l., H. convergens, and several spider taxa (Fig. 4B).

\subsection{Parasitoid populations and parasitism}

Eretmocerus eremicus Rose and Zolnerowich and Encarsia spp. (mainly E. meritoria Gahan) were found 
Table 5

Seasonal mean densities (per 50 sweeps) of arthropod predators, predator to prey ratios, and parasitism under various control regimes for B. tabaci and L. hesperus, Maricopa, AZ, 1999

\begin{tabular}{|c|c|c|c|c|c|c|c|c|c|c|c|}
\hline \multirow[b]{3}{*}{ Dictyna reticulata } & \multicolumn{4}{|c|}{ B. tabaci control regime } & \multicolumn{4}{|c|}{ Orthogonal contrasts ${ }^{\mathrm{a}}-F$ values } & \multicolumn{3}{|c|}{ L. hesperus control } \\
\hline & \multirow{2}{*}{$\begin{array}{l}\text { Buprofezin } \\
1 \text { st } \\
0.27 \pm 0.15\end{array}$} & \multirow{2}{*}{$\begin{array}{l}\text { Pyriproxyfen } \\
1 \text { st } \\
0.30 \pm 0.17\end{array}$} & \multirow{2}{*}{$\begin{array}{l}\text { Conven } \\
0.28 \pm 0.18\end{array}$} & \multirow{2}{*}{$\begin{array}{l}\text { Control } \\
0.33 \pm 0.19\end{array}$} & $\begin{array}{l}\text { IGR vs } \\
\text { Control }\end{array}$ & $\begin{array}{l}\text { IGR vs } \\
\text { Conven }\end{array}$ & $\begin{array}{l}\text { Conven vs } \\
\text { Control }\end{array}$ & \multirow{2}{*}{$\begin{array}{l}\text { Bup vs } \\
\text { Pyr } \\
0.03(0)\end{array}$} & \multirow{2}{*}{$\begin{array}{l}\text { No } \\
0.32 \pm 0.10\end{array}$} & \multirow{2}{*}{$\begin{array}{l}\text { Yes } \\
0.06 \pm 0.05\end{array}$} & \multirow{2}{*}{$\begin{array}{l}F^{\mathrm{a}} \\
11.0^{* *}(2)\end{array}$} \\
\hline & & & & & $0.62 \quad(1)$ & $0.99 \quad(1)$ & $1.17 \quad(1)$ & & & & \\
\hline Misumenops celer & $2.00 \pm 0.39$ & $1.70 \pm 0.23$ & $0.72 \pm 0.09$ & $2.97 \pm 0.18$ & $16.6^{*}(2)$ & $26.8^{* *}(2)$ & $64.2^{* *}(3)$ & $1.49(1)$ & $2.35 \pm 0.33$ & $1.59 \pm 0.06$ & $5.43^{*}(2)$ \\
\hline Jumping spiders & $0.47 \pm 0.13$ & $0.42 \pm 0.09$ & $0.17 \pm 0.05$ & $0.30 \pm 0.07$ & $1.19 \quad(1)$ & $5.88^{*}(2)$ & $0.58 \quad(0)$ & $0.26(0)$ & $0.42 \pm 0.11$ & $0.28 \pm 0.05$ & $1.66 \quad(0)$ \\
\hline Other spiders & $1.08 \pm 0.22$ & $1.72 \pm 0.34$ & $0.95 \pm 0.22$ & $1.38 \pm 0.26$ & $0.38 \quad(0)$ & $6.98 *(2)$ & 3.07 & $2.61(0)$ & $1.57 \pm 0.26$ & $0.81 \pm 0.13$ & $11.5^{* *}(2)$ \\
\hline Collops vittatus & $0.70 \pm 0.20$ & $0.48 \pm 0.18$ & $0.40 \pm 0.04$ & $0.68 \pm 0.05$ & $0.30 \quad(1)$ & $0.86 \quad(0)$ & $1.63 \quad(1)$ & $1.01(0)$ & $0.76 \pm 0.09$ & $0.39 \pm 0.06$ & $6.21^{*}(2)$ \\
\hline Other coccinellids & $0.45 \pm 0.14$ & $0.22 \pm 0.05$ & $0.13 \pm 0.08$ & $0.85 \pm 0.28$ & $6.92 *(1)$ & $5.43^{*}(1)$ & $13.2^{* *}(3)$ & $1.73(0)$ & $0.69 \pm 0.18$ & $0.24 \pm 0.04$ & $6.42^{*}(2)$ \\
\hline Anthicidae & $0.40 \pm 0.04$ & $0.23 \pm 0.11$ & $0.35 \pm 0.10$ & $0.47 \pm 0.14$ & $1.12 \quad(0)$ & $0.07 \quad(0)$ & $0.47 \quad(0)$ & $1.37(1)$ & $0.41 \pm 0.07$ & $0.35 \pm 0.06$ & $0.07 \quad(0)$ \\
\hline Geocoris punctipes & $1.40 \pm 0.15$ & $1.58 \pm 0.37$ & $0.30 \pm 0.09$ & $1.85 \pm 0.13$ & $1.01 \quad(0)$ & $19.3^{* *}(4)$ & $21.3^{* *}(4)$ & $0.52(0)$ & $1.89 \pm 0.18$ & $0.59 \pm 0.17$ & $35.2^{* *}(4)$ \\
\hline Geocoris pallens & $0.08 \pm 0.05$ & $0.20 \pm 0.08$ & $0.03 \pm 0.03$ & $0.05 \pm 0.03$ & $1.31 \quad(0)$ & $2.39 \quad(0)$ & $0.12 \quad(0)$ & $1.67(1)$ & $0.16 \pm 0.05$ & $0.04 \pm 0.02$ & $2.72 \quad$ (4) \\
\hline Orius tristicolor & $8.53 \pm 1.52$ & $7.45 \pm 0.36$ & $5.72 \pm 0.67$ & $9.25 \pm 1.36$ & $0.88 \quad(1)$ & $7.47^{*}(2)$ & $9.89^{* *}(3)$ & $1.35(1)$ & $10.4 \pm 1.25$ & $6.27 \pm 0.47$ & $21.9^{* *}(4)$ \\
\hline Nabis alternatus & $0.28 \pm 0.08$ & $0.23 \pm 0.05$ & $0.10 \pm 0.04$ & $0.25 \pm 0.06$ & $0.21 \quad(0)$ & $6.27^{*}(2)$ & $6.93^{* *}(2)$ & $0.19(0)$ & $0.30 \pm 0.04$ & $0.13 \pm 0.03$ & $6.89^{*}(2)$ \\
\hline Zelus renardii & $0.15 \pm 0.06$ & $0.05 \pm 0.03$ & $0.03 \pm 0.03$ & $0.15 \pm 0.12$ & 0.46 & $1.46 \quad(0)$ & $2.68 \quad(1)$ & $1.95(1)$ & $0.12 \pm 0.04$ & $0.07 \pm 0.03$ & $0.32 \quad(0)$ \\
\hline Sinea spp. & $0.05 \pm 0.03$ & $0.01 \pm 0.01$ & $0.01 \pm 0.01$ & $0.05 \pm 0.03$ & 0.80 & $0.80 \quad(0)$ & $2.40 \quad(1)$ & $2.40(0)$ & $0.03 \pm 0.02$ & $0.03 \pm 0.01$ & $0.00 \quad(0)$ \\
\hline Lygus hesperus & $23.3 \pm 2.32$ & $22.9 \pm 0.63$ & $14.9 \pm 1.36$ & $25.8 \pm 0.98$ & 2.20 & $26.3^{* *}(4)$ & $32.8^{* *}(4)$ & $0.08(0)$ & $31.6 \pm 2.35$ & $15.2 \pm 0.72$ & $95.0^{* *}$ (4) \\
\hline Pseudatomoscelis seriatus & $0.47 \pm 0.21$ & $0.30 \pm 0.15$ & $0.15 \pm 0.12$ & $0.55 \pm 0.18$ & 0.12 & $1.99 \quad(0)$ & $6.30^{*}(2)$ & $0.65(0)$ & $0.53 \pm 0.19$ & $0.17 \pm 0.06$ & $3.27 \quad(1)$ \\
\hline Spanogonicus albofasciatus & $0.03 \pm 0.03$ & $0.10 \pm 0.04$ & $0.08 \pm 0.05$ & $0.13 \pm 0.05$ & 1.49 & $0.06 \quad(0)$ & $0.72 \quad(0)$ & $1.61(0)$ & $0.15 \pm 0.02$ & $0.08 \pm 0.03$ & $0.09 \quad(0)$ \\
\hline Rhinacloa forticornis & $0.22 \pm 0.13$ & $0.15 \pm 0.06$ & $0.15 \pm 0.09$ & $0.33 \pm 0.13$ & $1.44 \quad(0)$ & $0.24 \quad(0)$ & $2.15 \quad(0)$ & $0.23(0)$ & $0.30 \pm 0.03$ & $0.09 \pm 0.03$ & $8.86^{* *}(2)$ \\
\hline Chrysoperla carnea s.l. & $3.88 \pm 0.60$ & $2.95 \pm 0.13$ & $2.38 \pm 0.30$ & $4.65 \pm 0.70$ & $7.03^{*}(2)$ & $6.90^{*}(2)$ & $16.5^{* *}(3)$ & $2.90(1)$ & $3.79 \pm 0.35$ & $3.05 \pm 0.23$ & $5.79^{*}(2)$ \\
\hline Drapetis nr. divergens & $31.3 \pm 2.99$ & $26.4 \pm 3.75$ & $22.6 \pm 3.74$ & $38.4 \pm 4.98$ & $6.00^{*}(1)$ & $9.91^{* *}(3)$ & $23.5^{* *}(4)$ & $1.52(0)$ & $37.6 \pm 4.08$ & $18.4 \pm 1.96$ & $63.1^{* *}(3)$ \\
\hline Pred:Prey Ratio (Eggs) ${ }^{\mathrm{b}}$ & $1.12 \pm 0.17$ & $0.98 \pm 0.14$ & $0.77 \pm 0.10$ & $0.69 \pm 0.19$ & $10.1^{* *}(2)$ & $3.11 \quad(2)$ & $1.49 \quad(0)$ & $2.00(0)$ & $0.68 \pm 0.04$ & $0.54 \pm 0.05$ & $5.19^{*}(3)$ \\
\hline Pred:Prey Ratio (Nymphs) ${ }^{\mathrm{b}}$ & $1.29 \pm 0.10$ & $1.39 \pm 0.11$ & $0.89 \pm 0.05$ & $1.01 \pm 0.09$ & $6.04^{*}(2)$ & $19.6^{* *}(3)$ & $4.43^{*}(1)$ & $0.02(1)$ & $0.91 \pm 0.08$ & $0.63 \pm 0.05$ & $18.0^{* *}(3)$ \\
\hline Pred:Prey Ratio (Adults) ${ }^{\mathrm{b}}$ & $19.7 \pm 3.32$ & $24.1 \pm 5.29$ & $20.3 \pm 3.72$ & $15.9 \pm 3.77$ & $5.89 *(2)$ & $0.05 \quad(0)$ & $2.94 \quad(1)$ & $0.25(1)$ & $14.4 \pm 3.56$ & $12.5 \pm 1.88$ & $3.44 \quad(1)$ \\
\hline Pred:Prey Ratio (All) ${ }^{\mathrm{b}}$ & $0.55 \pm 0.07$ & $0.51 \pm 0.05$ & $0.35 \pm 0.04$ & $0.40 \pm 0.08$ & $7.82^{*}(2)$ & $9.74^{* *}(3)$ & $0.07 \quad(0)$ & $0.72(0)$ & $0.37 \pm 0.03$ & $0.25 \pm 0.02$ & $6.15^{*}(3)$ \\
\hline Prop. Parasitism ${ }^{\mathrm{c}}$ & $0.02 \pm 0.01$ & $0.03 \pm 0.01$ & $0.04 \pm 0.01$ & $0.03 \pm 0.01$ & $0.20 \quad(0)$ & $3.46 \quad(1)$ & $1.54 \quad(1)$ & $0.03(1)$ & $0.04 \pm 0.01$ & $0.02 \pm 0.01$ & $0.63 \quad(0)$ \\
\hline
\end{tabular}

Values are means seasonal densities \pm SE over five post-treatment sample dates in four replicate plots $(n=4)$. IGR $=$ buprofezin + pyriproxyfen; Bup $=$ buprofezin 1 st regime; Pyr $=$ pyriproxyfen 1st regime; Conven $=$ conventional whitefly control regime.

${ }^{a}$ Repeated-measures ANOVA using Proc Mixed (Littell et al., 1996); d.f. estimated by Satterthwaite's correction; ${ }^{*} P<0.05$; ${ }^{* *} P<0.01$; values in parentheses indicate the number of sample dates (out of 8 total) on which the $F$-value was significant $(P<0.05)$.

${ }^{\mathrm{b}}$ Quotient of all arthropod predators per 50 sweeps to B. tabaci eggs, nymphs, adults or all life stages combined per leaf. For $L$. hesperus control contrasts, the ratio does not include densities of L. hesperus or P. seriatus.

${ }^{\mathrm{c}}$ Proportion of 4 th instar B. tabaci nymphs parasitized per leaf. 
A

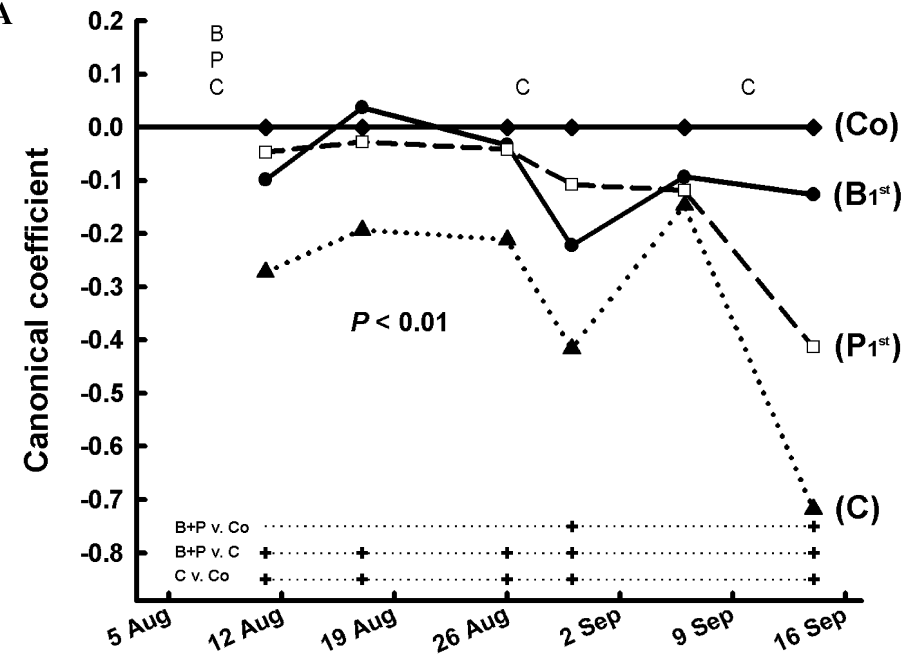

B

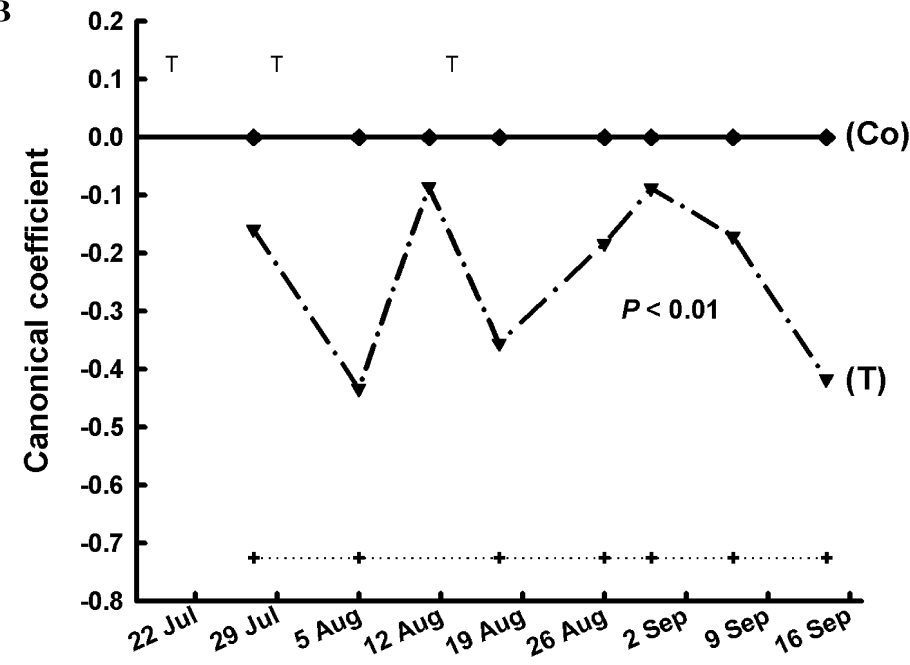

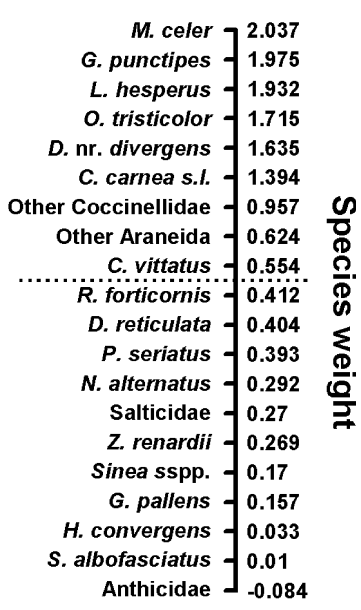

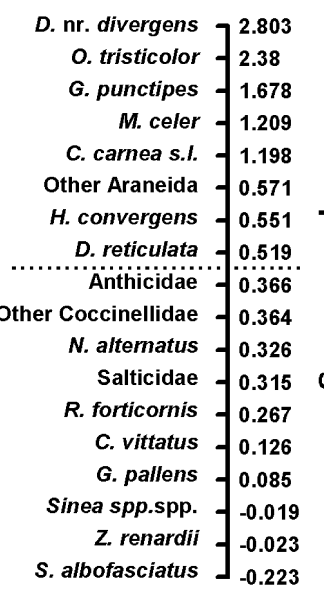

Fig. 4. Principal response curves (PRC) showing the main effects of (A) whitefly control (only post-application dates for whitefly insecticides are shown), and (B) L. hesperus control (only post-application dates for $L$. hesperus insecticides are shown) on the predatory arthropod community during the growing season, 1999, Maricopa, AZ. The PRC show the effect of each treatment regime relative to the untreated control (Co) which is represented by the $y=0$ line. The greater the species weight the more the response for that species resembles the PRC. Negative weights indicate an opposite pattern and weights between -0.5 and 0.5 indicate a weak response or a response unrelated to the PRC. The $P$-value denotes the significance of the PRC analysis over all dates based on an $F$-type permutation test. The plus symbols at the base of each graph denote the significance $(P<0.05)$ of the indicated contrast on each date determined by $F$-type permutation test; letters along the top of each graph denote the timing of applications of buprofezin (B), pyriproxyfen (P), or conventional insecticides for whitefly (C) or L. hesperus (T). There were no significant differences between the two IGRs on any date and so contrasts are not shown.

attacking $B$. tabaci at our study site. Eretmocerus spp. were dominant, comprising over 85,59 , and $55 \%$ of all parasitoids sampled in 1997, 1998, and 1999, respectively. As with predators there were no significant $(P>0.05)$ interactions between $B$. tabaci and L. hesperus control regimes in parasitism rates and so only main effects are presented. The proportion of parasitized hosts varied widely in 1997 ranging from $<0.05$ on several sample dates in all regimes to $>0.30$ by midAugust in the pyriproxyfen regime (Fig. 5A). Averaged over the season, there were few significant differences among whitefly control regimes with the highest rate of parasitism being observed in the pyriproxyfen regime
(Tables 2 and 3). In 1998, rates of parasitism increased steadily over the season in all whitefly control regimes with rates exceeding 0.25 by mid September (Fig. 5C). Seasonal average rates of parasitism did not differ significantly $(P>0.05)$ among whitefly control regimes (Table 4), although rates of parasitism differed significantly, but not consistently, on several sample dates. Rates of parasitism were low in 1999, rarely exceeding 0.10 in any regime and there were no significant differences $(P>0.05)$ among whitefly control regimes (Table 5, Fig. 5E). The rate of parasitism was significantly higher with L. hesperus suppression in 1997 (Table 2), but significantly higher without $L$. hesperus control in 

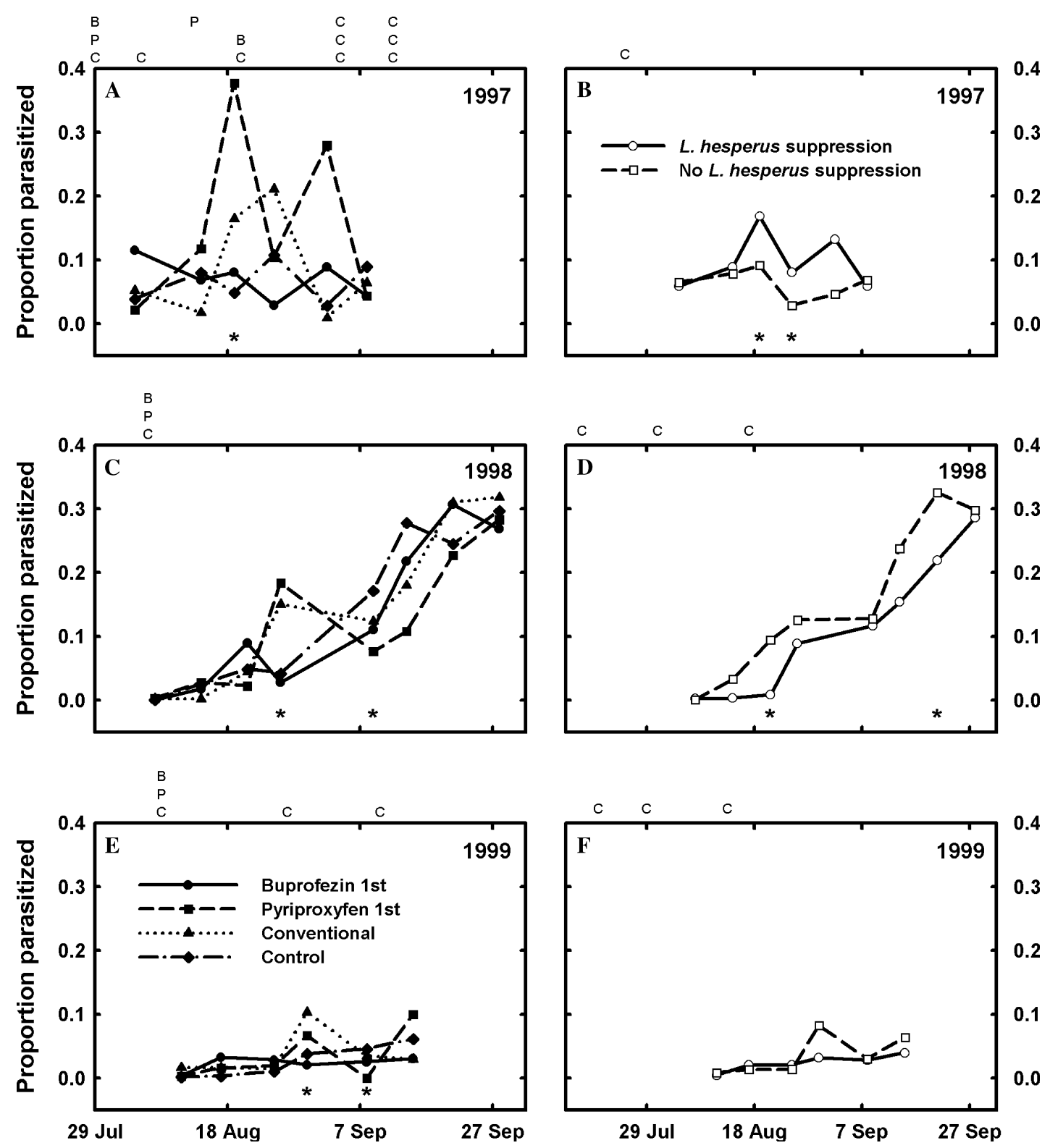

Fig. 5. The main effects of B. tabaci (A, C, E) and L. hesperus (B, D, F) control regimes on proportional parasitism by aphelinid parasitoids attacking B. tabaci during the growing season, 1997-1999, Maricopa, AZ. Only post-application dates for whitefly insecticides are shown. Asterisks along the bottom of each graph denote dates on which significant $(P<0.05)$ treatment differences were observed; letters along the top of each graph denote the timing of applications of buprofezin (B), pyriproxyfen (P) or conventional $(\mathrm{C})$ insecticides. Results in A are based solely on data from split-plots receiving $L$. hesperus control, because the split-plot design was incomplete in 1997.

1998 (Table 4). These patterns resulted largely from relatively small differences in parasitism on several sample dates and the differing intervals between samples and $L$. hesperus spray applications in the two years (Figs. 5B and D). There was no effect $(P>0.05)$ of $L$. hesperus control on rates of parasitism in 1999 (Table 5, Fig. 5F).

Rates of parasitism varied significantly $(P<0.05)$ over time, and there were significant whitefly control regime by date interactions in all years. These interactions were due to the inconsistent effects of the treatment regimes over the course of each season (Fig. 5). There were no significant $(P>0.05)$ interactions between $L$. hesperus control regimes and time.

\subsection{Overall impact of insecticides}

To summarize results from all three years, indices were calculated based on statistically significant changes in seasonal densities of each predator taxa, rates of parasitism, and predator:prey ratios relative to the untreated control (Table 6). M. celer, other coccinellids, 
Table 6

Meta-analysis of the effect of $B$. tabaci and $L$. hesperus control on arthropod predators, predator to prey ratios, and parasitism over a three year period, Maricopa, AZ, 1997-1999

\begin{tabular}{|c|c|c|c|}
\hline \multirow[b]{3}{*}{ Dictyna reticulata } & \multicolumn{2}{|c|}{ B. tabaci control regime } & \multirow[t]{2}{*}{ L. hesperus control } \\
\hline & IGR 1st & Conventional & \\
\hline & $0^{\mathrm{a}} \quad(0.74)$ & $0 \quad(0.28)$ & $-0.46(0.37)$ \\
\hline Misumenops celer & $-0.13(0.85)$ & $-0.58 \quad(0.42)$ & $-0.48 \quad(0.52)$ \\
\hline Jumping spiders & $0 \quad(1.81)$ & $0 \quad(0.54)$ & $-0.10(0.69)$ \\
\hline Other spiders & $0.18(1.13)$ & $-0.31 \quad(0.73)$ & $-0.28 \quad(0.60)$ \\
\hline Collops vittatus & $\begin{array}{ll}0 & (0.80)\end{array}$ & $-0.46(0.40)$ & $-0.16(0.65)$ \\
\hline Hippodamia convergens & $0 \quad(0.59)$ & $0 \quad(0.23)$ & $-0.22(0.44)$ \\
\hline Other coccinellids & $-0.20(0.84)$ & $-0.28 \quad(0.67)$ & $-0.53(0.27)$ \\
\hline Anthicidae & $0 \quad(1.20)$ & $-0.26(0.55)$ & $0 \quad(0.88)$ \\
\hline Geocoris punctipes & $-0.22(0.70)$ & $-0.69(0.31)$ & $-0.68 \quad(0.32)$ \\
\hline Geocoris pallens & $0 \quad(1.37)$ & $-0.22(0.65)$ & $-0.38 \quad(0.37)$ \\
\hline Orius tristicolor & $0 \quad(0.85)$ & $-0.42(0.58)$ & $-0.18(0.80)$ \\
\hline Nabis alternatus & $-0.24(0.78)$ & $-0.47(0.34)$ & $-0.36(0.75)$ \\
\hline Zelus renardii & $0 \quad(0.70)$ & $-0.30(0.38)$ & $-0.15(0.61)$ \\
\hline Sinea spp. & $0 \quad(0.89)$ & $-0.32(0.75)$ & $0 \quad(0.80)$ \\
\hline Lygus hesperus & $-0.14(0.84)$ & $-0.42(0.58)$ & $-0.48(0.52)$ \\
\hline Pseudatomoscelis seriatus & $0 \quad(0.69)$ & $-0.69(0.31)$ & $-0.39(0.38)$ \\
\hline Spanogonicus albofasciatus & $-0.21 \quad(0.69)$ & $-0.25(0.41)$ & $0 \quad(0.76)$ \\
\hline Rhinacloa forticornis & $\begin{array}{ll}0 & (0.45)\end{array}$ & $\begin{array}{ll}0 & (0.39)\end{array}$ & $-0.43(0.23)$ \\
\hline Chrysoperla carnea s.l. & $-0.25(0.71)$ & $-0.37(0.63)$ & $-0.31 \quad(0.69)$ \\
\hline D. nr. divergens & $-0.24(0.71)$ & $-0.44(0.56)$ & $-0.45(0.55)$ \\
\hline Pred:Prey Ratio (Eggs) & $0.17(1.40)$ & $0 \quad(1.19)$ & $-0.25(0.75)$ \\
\hline Pred:Prey Ratio (Nymphs) & $0.37(1.40)$ & $0.04(0.97)$ & $-0.30(0.70)$ \\
\hline Pred:Prey Ratio (Adults) & 0.49 (1.49) & $0.19(1.40)$ & $-0.14(0.79)$ \\
\hline Pred:Prey Ratio (All) & $0.11(1.32)$ & $0 \quad(1.06)$ & $-0.31(0.69)$ \\
\hline Proportional parasitism & $(1.02)$ & $(1.00)$ & $0.12(0.95)$ \\
\hline
\end{tabular}

${ }^{\mathrm{a}}$ Index is calculated as the mean of $p_{i} s_{i}$ over all three years, where $p$ is the proportional change in predator density, parasitism, or the predatorprey ratio in a given insecticide regime relative to the control in year $i$ and $s$ is a dummy variable indicating the statistical significance $(s=1)$ or nonsignificance $(s=0)$ of the reduction based on ANOVA results in year $i$. Values in parentheses indicate the mean (all years) density, ratio or parasitism rate as a proportion of the control level.

G. punctipes, $N$. alternatus, L. hesperus, S. albofasciatus, C. carnea s.l., and $D$. nr. divergens were all significantly reduced by the use of either IGR regime relative to the control in at least one year. For the "other spiders" group, densities were significantly higher under the IGR regimes. These same predators plus eight additional taxa were significantly reduced by the conventional insecticide regime relative to the control. In all instances the negative impact of conventional insecticides was greater than that of the IGRs. Mean predator population densities in insecticide regimes viewed as a proportion of the untreated control (Table 6, values in parentheses) further emphasize the selective nature of the IGRs. Average densities of some taxa (jumping spiders, other spiders, anthicid beetle, G. pallens) were higher in the IGR regimes than in the untreated control. Predator:prey ratios based on each B. tabaci stage separately and all stages combined increased with the use of IGRs with changes being largest for ratios based on nymphs and adults. Predator:prey ratios based on nymphs or adults increased slightly in the conventional regime compared with the control and were 1.3 to 1.5 times higher in IGR regimes than in the control. With the exception of anthicid beetles, Sinea spp. and S. albofasciatus, the application of insecticides for control of $L$. hesperus significantly reduced densities of all predator taxa and all predator:prey ratios (Table 6). In many cases these reductions were relatively large. Parasitism increased slightly with $L$. hesperus control, but was unaffected by any whitefly insecticide regime.

\section{Discussion}

Enhancing the role of biological control within insecticide-dominated management systems will require insecticides and application methods that improve physiological and/or ecological selectivity. We have shown that simple adjustments in action thresholds for application of conventional insecticides against B. tabaci in cotton can reduce disruption of natural enemy populations (Naranjo et al., 2002). Commercialscale field studies have also shown that management strategies based on the initial use of the IGRs buprofezin and pyriproxyfen preserves natural enemies compared with sole reliance on conventional insecticide 
mixtures (Naranjo et al., 2003). Our results here confirm and augment these findings, and further quantify the selectivity of these IGRs relative to an untreated control.

We observed significant and immediate reductions in densities of most of the natural enemies examined over extended portions of the growing season with use of broad-spectrum, conventional insecticides. Conversely, the initial use of either buprofezin and pyriproxyfen for pest control conserved natural enemies, particularly arthropod predators. Nonetheless, densities of some predator taxa were reduced with use of the two IGRs in comparison with the untreated control. Densities of $C$. carnea s.1., D. nr. divergens, several spiders and coccinellids, the heteropteran predators G. punctipes and $N$. alternatus, and the omnivores L. hesperus and S. albofasciatus were significantly reduced under IGR regimes in at least one out of three years. In most instances, reductions in these taxa were much greater with use of conventional insecticides. Further, PRC analyses suggest that significant reductions in predator densities started many weeks after IGR applications. In 1997 reductions in the IGR regimes were associated with sprays of conventional insecticides in these regimes in early to mid-September (see Fig. 2A). However, only single applications of either buprofezin or pyriproxyfen were required in the IGR control regimes in 1998 and 1999 and reductions only occurred after 5 and 3 weeks, respectively (see Figs. 3A and 4A). These patterns suggest that reductions in predator populations may have been associated with more subtle and latent toxicological effects, and/or various indirect effects such as a reduction in prey density.

Field studies of insecticide effect on natural enemies integrate many factors, including direct toxicological effects and indirect effects such as reductions in prey availability. Direct toxicological effects of both IGRs have been shown in laboratory bioassays of various natural enemy species. Buprofezin reduced survival and prolonged development in first instar C. rufilabris (Burmeister) (Liu and Chen, 2000) and pyriproxyfen had similar effects on eggs and larvae (Chen and Liu, 2002). However, Balasubramani and Regupathy (1994) reported no effect of buprofezin on larval stages of $C$. carnea. Pyriproxyfen suppressed adult emergence of Podisus maculiventris (Say) (Declercq et al., 1995) and egg hatch in Elatophilus hebraicus Pericart (Mendel et al., 1994). Pyriproxyfen exposure in the nymphal stage caused some deformities in adult $G$. punctipes, but not $O$. insidiosus (Say), and no effects on reproduction were observed for either species (Naranjo and Prabhaker, unpublished). Likewise, Delbeke et al. (1997) and Nagai (1990) reported no effects of pyriproxyfen on several Orius spp. Buprofezin had no measurable effects on survival, molting or reproduction of G. punctipes or O. insidiosus (Naranjo and Prabhaker, unpublished). The most dramatic nega- tive effects of these IGRs have been demonstrated for coccinellid beetles inhabiting perennial systems (Hattingh and Tate, 1995; Magagula and Samways, 2000; Mendel et al., 1994; Smith et al., 1999). Although coccinellids were rare at our study site, we observed no consistent negative effects of either IGR on these taxa.

Although direct toxicological effects of these IGRs cannot be dismissed, the relatively long interval (3-5 weeks) between application of either buprofezin or pyriproxyfen and reductions in predator populations suggests that other factors, such as reductions in prey density, may play a greater role. Many of the predators we examined are general feeders (van den Bosch and Hagen, 1966; Whitcomb and Bell, 1964), and B. tabaci is one of the most abundant arthropods occurring in our study area. Densities of B. tabaci nymphs were reduced soon after the application of either IGR, and egg and adult densities dropped within several weeks following applications. The gradual decline in predator populations in the IGR regimes relative to the untreated control over the season (see Figs. 2-4) was coincident with a similar decline in densities of whitefly prey. In contrast, immediate reductions in many predator taxa followed applications of conventional insecticides for whitefly suppression. The more consistent declines in $C$. carnea s.l., and D. nr. divergens in the IGR regimes may be related to the stronger affinity of these predators with whitefly prey. The empidid fly $D$. nr. divergens $s p$. was first discovered in association with large populations of B. tabaci in Arizona cotton and preliminary laboratory studies suggested that they could suppress adult B. tabaci and subsequent oviposition (Butler and Henneberry, 1993). Further laboratory feeding studies suggest that this species prefers to prey on adult B. tabaci (Hagler, 2002). C. carnea s.l. readily feeds on B. tabaci (Butler and Henneberry, 1988), and adult lacewings are known to be attracted to insect honeydews and artificial sugar supplements (e.g., Evans and Swallow, 1993; Hagen, 1986). Reductions in one of the most abundant prey in the system also may have increased opportunities for intraguild predation (Eubanks, 2001; Rosenheim et al., 1993) among predator species, further contributing to reductions in densities of some predators.

Rates of parasitism by aphelinid wasps were generally low, and neither the conventional nor IGR control regimes altered parasitism in a consistent manner. In contrast, a commercial-scale study showed that rates of parasitism were higher in fields sprayed with either buprofezin or pyriproxyfen compared with those sprayed with conventional insecticides (Naranjo et al., 2003). Field studies in Israel and southern California showed that rates of parasitism were unaffected by the use of broad-spectrum insecticides (Gerling and Naranjo, 1998). Because hosts must be present to measure parasitism, they suggested that insecticides affected 
populations of both hosts and parasitoids equally, resulting in relatively stable levels of parasitism regardless of treatment. It is not clear that such a phenomenon was operating here as direct toxicological effects of the IGRs on parasitoids in laboratory bioassays is equivocal. Buprofezin caused mortality in early larval stages of Encarsia luteola Howard, E. eremicus and E. tejanus Rose and Zolnerowich (Gerling and Sinai, 1994; Hoddle et al., 2001; Jones et al., 1998), and pyriproxyfen reduced survival of young larvae of $E$. eremicus and $E$. luteola (Gerling and Sinai, 1994; Hoddle et al., 2001) and pupae of E. formosa Gahan (Liu and Stansly, 1997). However, buprofezin was benign to adults of several species of Eretmocerus and Encarsia (Hoddle et al., 2001; Jones et al., 1995) and pyriproxyfen was non-toxic to several species of Encarsia treated in the larval or adult stage (Liu and Stansly, 1997). Reductions in host density from insecticides may have influenced densities and/or searching behaviors of adult parasitoids leading to inconsistent changes in rates of parasitism. Lack of treatment differences could also be related to the relatively poor resolution provided by simple leaf samples for measuring parasitism (Naranjo, 2001). Finally, the relatively small size of plots in this study compared with those of Naranjo et al. (2003) may have facilitated interplot movement of adult parasitoids.

Although parasitoid to host ratios remained relatively consistent across treatments, higher ratios of predators to whitefly prey were generally observed with the use of IGRs compared with both the untreated control and the conventional control regime. Thus, even though use of the IGRs was associated with reductions in some predator populations, these materials were much more detrimental to whiteflies leading to predator:prey ratios more favorable to biological control. The tangible benefits of this conservation were not estimated directly in this study. However, in companion life table studies conducted in the same plots, we have shown that rates of natural enemy-induced mortality, primarily predation, on immature $B$. tabaci were significantly higher with the use of IGRs compared with conventional insecticides and this additional mortality contributed significantly to season-long suppression of $B$. tabaci in the IGR regimes (Naranjo, 2001; Naranjo and Ellsworth, unpublished). In addition, rates of predation in these life table studies were positively correlated with predator abundance, indicating that the level of conservation was directly related to pest mortality.

Cotton agroecosystems are characterized by multiple key pests. The use of transgenic cotton expressing $B a$ cillus thuringiensis Berliner toxins in our study eliminated the need for additional insecticides for control of pink bollworm, Pectinophora gossypiella (Saunders) and other lepidopteran pests (Ellsworth and Jones, 2001). Although we evaluated $L$. hesperus as a non-target insect in terms of whitefly control, it is clear that this species remains a continual threat to cotton production in $\mathrm{Ar}$ izona and California and there are currently no selective technologies for population suppression (Ellsworth, 2000). The addition of conventional insecticides for control of $L$. hesperus here dramatically reduced populations of many natural enemies. Although the lack of statistical interaction between whitefly and $L$. hesperus control regimes indicated that selectivity of the IGRs for whitefly control is realized even with the use of insecticides for $L$. hesperus, the overall benefits of this selectivity were diminished. In practice, these results emphasize the need to strictly follow available decision aids for L. hesperus suppression (Ellsworth, 2000). In research, our results highlight the importance of examining insecticide selectivity within the context of realistic pest management systems.

Buprofezin and pyriproxyfen are currently an integral component of pest management for B. tabaci in the western US, and their use is being widely adopted in Australian cotton where outbreaks of $B$. tabaci have recently occurred (Kelly et al., 2002). They are highly efficacious (Ellsworth and Naranjo, 1999; Ellsworth et al., 1998), their use delays or eliminates the need for conventional insecticides as part of an insecticide resistance management plan (Dennehy and Williams, 1997; Ellsworth et al., 1996a), and, as we have shown, they are highly selective. Pyriproxyfen and buprofezin were granted full registration in 1998 and 2002, respectively, and both materials are being widely used by producers in Arizona (Agnew and Baker, 2001; Agnew et al., 2000; Ellsworth and Martinez-Carrillo, 2001). The additional use of transgenic cotton further conserves natural enemy populations (Moar et al., 2002; Naranjo, 2002) thereby providing for selective control of two key pests. Since the introduction of these selective pest control methods in 1996, insecticide use in Arizona cotton declined nearly 85\% from 1995 to 1999 (Ellsworth and Jones, 2001). In turn, this reduction in overall insecticide use in western cotton production systems is enabling true integrated control of B. tabaci, and may facilitate the further evolution of biologically based management of many pests founded on conservation and other approaches to biological control.

\section{Acknowledgments}

We thank John Ruberson (Univ. Georgia) and Walker Jones (USDA-ARS, Weslaco, TX) for helpful comments on earlier drafts of this manuscript, Bruce Mackey (USDA-ARS, Albany, CA) for advice on statistical analyses, Kim Hoelmer (USDA-ARS, Montpellier, France) for identification of parasitoids, and Robert Nichols (Cotton Incorporated) for consistent and crucial support of our whitefly management research. We also thank Daniel Ashton, Virginia Barkley, Kim 
Beimfohr, Jeff Cantrell, Sunny Carrington, Rochelle Christensen, Shana England, Johnny Fearn, Celso Jara, Stephanie Jones, Dan Langhorst, Scott Machtley, Jeanette Martin, Donna Meade, Gregory Owens, and Sally Wright for expert technical assistance. Partial support was provided by USDA-CREES, Pest Management Alternatives Special Projects, NAPIAP (Western Region), Western Region IPM Special Projects, and Cotton Incorporated.

\section{References}

Abdelrahman, A.A., Munir, B., 1989. Sudanese experience in integrated pest management of cotton. Insect Sci. Appl. 10, 787794.

Agnew, C.W., Sterling, W.L., Dean, D.A., 1982. Influence of cotton nectar on red imported fire ants and other predators. Environ. Entomol. 11, 629-634.

Agnew, G.K., Baker, P.B., 2001. Pest and pesticide usage patterns in Arizona cotton production. In: Dugger, P., Richter, D. (Eds.), Proceedings Beltwide Cotton Conferences. National Cotton Council, Memphis, Tennessee, pp. 1046-1054.

Agnew, G.K., Frisvold, G.B., Baker, P.B., 2000. Adoption of insect growth regulators in Arizona cotton: determinants and economic implications. In: Dugger, P., Richter, D. (Eds.), Proceedings Beltwide Cotton Conferences. National Cotton Council, Memphis, Tennessee, pp. 361-364.

Balasubramani, V., Regupathy, A., 1994. Safety of the insect growth regulator buprofezin to the egg parasitoid Trichogramma chilonus and the predator Chrysoperla carnea. In: Goel, S.C. (Ed.), Insect and Environment V. 5: Biological control of insect pests. Uttar Pradesh Zoological Society, India, pp. 177-180.

Butler Jr., G.D., 1965. Spanogonicus albofasciatus as an insect and mite predator. J. Kansas Entomol. Soc. 38, 70-75.

Butler Jr., G.D., Henneberry, T.J., 1988. Laboratory studies on Chrysopa carnea predation on Bemisia tabaci. Southwest. Entomol. 13, 165-170.

Butler Jr., G.D., Henneberry, T.J., 1993. Sweetpotato whitefly natural enemies: parasite surveys in urban areas and cotton fields and identification of a new predator. In: Cotton, A College of Agriculture Report, Series P-94, University of Arizona, Tucson, pp. 256-257.

Castane, C., Arino, J., Arno, J., 1996. Toxicity of some insecticides and acaricides to the predatory bug Dicyphus tamaninii. Entomophaga 41, 211-216.

Chen, T.Y., Liu, T.X., 2002. Susceptibility of immature stages of Chrysoperla rufilabris (Neurop., Chrysopidae) to pyriproxyfen, a juvenile hormone analog. J. Appl. Entomol. 126, 125-129.

Croft, B.A., 1990. Arthropod Biological Control Agents and Pesticides. Wiley, New York.

Declercq, P., Decock, A., Tirry, L., Vinuela, E., Degheele, D., 1995. Toxicity of diflubenzuron and pyriproxyfen to the predatory bug Podisus maculiventris. Entomol. Exp. Appl. 74, 17-22.

Delbeke, F., Vercruysse, P., Tirry, L., DeClercq, P., Degheele, D., 1997. Toxicity of diflubenzuron, pyriproxyfen, imidacloprid and diafenthiuron to the predatory bug Orius laevigatus (Het.: Anthocoridae). Entomophaga 42, 349-358.

Dennehy, T.J., Williams, L., 1997. Management of resistance in Bemisia in Arizona cotton. Pest. Sci. 51, 398-406.

Devine, G.J., Ishaaya, I., Horowitz, A.R., Denholm, I., 1998. Effects of piperonyl butoxide on Bemisia tabaci Genn. (Homoptera : Aleyrodidae): mortality, development, parasitism and predation in Israeli cotton fields. Crop Prot. 17, 717-726.
Dhadialla, T.S., Carlson, G.R., Le, D.P., 1998. New insecticides with ecdysteroidal and juvenile hormone activity. Annu. Rev. Entomol. 43, 545-569.

Ellsworth, P.C., 2000. Lygus control decision aids for Arizona cotton, in: Cotton, A College of Agriculture Report, Series P-121, University of Arizona, Tucson, pp. 269-280.

Ellsworth, P.C., Jones, J.S., 2001. Cotton IPM in Arizona: a decade of research, implementation \& education. In: Dugger, P., Richter, D. (Eds.), Proceedings Beltwide Cotton Conferences. National Cotton Council, Memphis, Tennessee, pp. 1088-1096.

Ellsworth, P.C., Martinez-Carrillo, J.L., 2001. IPM for Bemisia tabaci: a case study from North America. Crop Prot. 20, 853-869.

Ellsworth, P.C., Naranjo, S.E., 1999. Whitefly management with insect growth regulators and the influence of Lygus controls. In: Cotton, A College of Agriculture Report, Series P-116, University of Arizona, Tucson, pp. 339-354.

Ellsworth, P.C., Dennehy, T.J., Nichols, R.L., 1996a. Whitefly management in Arizona cotton 1996, IPM Series No. 3, Publ. 196004, Cooperative Extension, University of Arizona, Tucson.

Ellsworth, P., Diehl, J., Dennehy, T., Naranjo, S., 1995. Sampling sweetpotato whiteflies in cotton, IPM Series No. 2, Cooperative Extension, University of Arizona, Tucson (revised).

Ellsworth, P.C., Diehl, J.W., Naranjo, S.E., 1996b. Sampling sweetpotato whitefly nymphs in cotton, IPM Series No. 6, Cooperative Extension, University of Arizona, Tucson.

Ellsworth, P.C., Naranjo, S.E., Castle, S.J., Hagler, J., Henneberry, T.J., 1998. Whitefly management in Arizona: looking at whole systems. In: Cotton, A College of Agriculture Report, Series P-112, University of Arizona, Tucson, pp. 311-318.

Eubanks, M.D., 2001. Estimates of the direct and indirect effects of red imported fire ants on biological control in field crops. Biol. Control 21, 35-43.

Evans, E.W., Swallow, J.G., 1993. Numerical responses of natural enemies to artificial honeydew in Utah alfalfa. Environ. Entomol. 22, 1392-1401.

Faria, M., Wraight, S.P., 2001. Biological control of Bemisia tabaci with fungi. Crop Prot. 20, 767-778.

Gerling, D., Mayer, R.T. (Eds.), 1996. Bemisia 1995: Taxonomy, Biology, Damage, Control and Management. Intercept Limited, Andover, UK.

Gerling, D., Naranjo, S.E., 1998. The effect of insecticide treatments in cotton fields on the levels of parasitism of Bemisia tabaci (Gennadius) sl. Biol. Control 12, 33-41.

Gerling, D., Sinai, P., 1994. Buprofezin effects on two parasitoid species of whitefly (Homoptera, Aleyrodidae). J. Econ. Entomol. $87,842-846$.

Gerling, D., Alomar, O., Arnó, J., 2001. Biological control of Bemisia tabaci using predators and parasitoids. Crop Prot. 20, 779-799.

Hagen, K.S., 1986. Ecosystem analysis: plant cultivars (HPR), entomophagous species and food supplements. In: Boethel, D.J., Eikenbary, R.D. (Eds.), Interactions of Plant Resistance and Parasitoids and Predators of Insects. Ellis Horwood Limited, Chichester, West Sussex, England, pp. 151-197.

Hagler, J.R., 2002. Foraging behavior, host stage selection and gut content analysis of field collected Drapetis nr. divergens: a predatory fly of Bemisia argentifolii. Southwest. Entomol. 27, 241-249.

Hagler, J.R., Naranjo, S.E., 1994a. Determining the frequency of heteropteran predation on sweetpotato whitefly and pink bollworm using multiple ELISAs. Entomol. Exp. Appl. 72, 63-70.

Hagler, J.R., Naranjo, S.E., 1994b. Qualitative survey of two Coleopteran predators of Bemisia tabaci (Homoptera, Aleyrodidae) and Pectinophora gossypiella (Lepidoptera, Gelechiidae) using a multiple prey gut content ELISA. Environ. Entomol. 23, 193197.

Hattingh, V., Tate, B., 1995. Effects of field-weathered residues of insect growth regulators on some Coccinellidae (Coleoptera) of 
economic importance as biocontrol agents. Bull. Entomol. Res. 85, 489-493.

Hoddle, M.S., van Driesche, R.G., Lyon, S.M., Sanderson, J.P., 2001. Compatibility of insect growth regulators with Eretmocerus eremicus for whitefly control on poinsettias: I. Laboratory assays. Biol. Control 20, 122-131.

Hoelmer, K.A., 1996. Whitefly parasitoids: can they control field populations of Bemisia? In: Gerling, D., Mayer, R.T. (Eds.), Bemisia 1995: Taxonomy, Biology, Damage, Control and Management. Intercept Limited, Andover, UK, pp. 451476.

Hoelmer, K.A., Kirk, A.A., 1999. An overview of natural enemy explorations and evaluations for Bemisia in the U.S. Bull. OILB/ SROP (IOBC/WPRS) 22, 109-112.

Ishaaya, I., Horowitz, A.R., 1992. Novel phenoxy juvenile hormone analog (pyriproxyfen) suppresses embryogenesis and adult emergence of sweetpotato whitefly (Homoptera: Aleyrodidae). J. Econ. Entomol. 85, 2113-2117.

Ishaaya, I., Mendelson, Z., Melamed-Madjar, V., 1988. Effect of buprofezin on embryogenesis and progeny formation of sweetpotato whitefly (Homoptera: Aleyrodidae). J. Econ. Entomol. 81, 781-784.

Jones, W.A., Ciomperlik, M.A., Wolfenbarger, D.A., 1998. Lethal and sublethal effects of insecticides on two parasitoids attacking Bemisia argentifolii (Homoptera: Aleyrodidae). Biol. Control 11, $70-76$.

Jones, W.A., Wolfenbarger, D.A., Kirk, A.A., 1995. Response of adult parasitoids of Bemisia tabaci to leaf residues of selected cotton insecticides. Entomophaga 40, 153-162.

Kelly, D., Wilson, L., Parlato, D., 2002. Management of silverleaf whitefly in Australian cotton. Australian Cotton Cooperative Research Centre No. 13. Available from (URL: http://www.cotton.crc.org.au/Assets/PDFfiles/Wflymng.pdf).

Kirk, A.A., Lacey, L.A., 1996. A systematic approach to foreign exploration for natural enemies of Bemisia and some current results. In: Gerling, D., Mayer, R.T. (Eds.), Bemisia 1995: Taxonomy, Biology, Damage, Control and Management. Intercept Limited, Andover, UK, pp. 531-533.

Kirk, A.A., Lacey, L.A., Goolsby, J.A., 2001. Classical biological control of Bemisia and successful integration of management strategies in the United States. In: Harris, K.F., Smith, O., Duffus, J.E. (Eds.), Virus-Insect-Plant Interactions. Academic Press, San Diego, CA, pp. 309-331.

Littell, R.C., Milliken, G.A., Stroup, W.W., Wolfinger, R.D., 1996. SAS System for Mixed Models. SAS Institute, Cary, NC.

Liu, T.X., Chen, T.Y., 2000. Effects of the chitin synthesis inhibitor buprofezin on survival and development of immatures of Chrysoperla rufilabris (Neuroptera: Chrysopidae). J. Econ. Entomol. 93, 234-239.

Liu, T.X., Stansly, P.A., 1997. Effects of pyriproxyfen on three species of Encarsia (Hymenoptera: Aphelinidae), endoparasitoids of Bemisia argentifolii (Homoptera: Aleyrodidae). J. Econ. Entomol. 90, 404-411.

Magagula, C.N., Samways, M.J., 2000. Effects of insect growth regulators on Chilocorus nigritus (Fabricius) (Coleoptera: Coccinellidae), a non-target natural enemy of citrus red scale, Aonidiella aurantii (Maskell) (Homoptera: Diaspididae), in southern Africa: evidence from laboratory and field trials. African Entomol. 8, 4756.

Mendel, Z., Blumberg, D., Ishaaya, I., 1994. Effects of some insect growth regulators on natural enemies of scale insects. Entomophaga 39, 199-209.

Moar, W., Eubanks, M., Freeman, B., Turnipseed, S., Ruberson, J., Head, G., Effects of $B t$ cotton on natural enemies in the Southeast USA. In: Hoddle, M. (Ed.), Proceedings 3rd California Conference on Biological Control, 15-16 August 2002, Davis, CA, pp. 31-32.
Nagai, K., 1990. Effects of a juvenile hormone mimic material 4phenoxyphenyl (RS)-2(2-pyridyloxy) propyl ether, on Thrips palmi and its predator Orius spp. Appl. Entomol. Zool. 25, 199-204.

Naranjo, S.E., 2001. Conservation and evaluation of natural enemies in IPM systems for Bemisia tabaci. Crop Prot. 20, 835852.

Naranjo, S.E., 2002. Arthropod communities and transgenic cotton in the Western US. In: Hoddle, M. (Ed.), Proceedings 3rd California Conference on Biological Control, 15-16 August 2002, Davis, CA, pp. 33-38.

Naranjo, S.E., Ellsworth, P.C. (Eds.), 2001. Challenges and opportunities for pest management of Bemisia tabaci in the new century. Crop Prot. (special issue) 20, 707-869.

Naranjo, S.E., Flint, H.M., 1994. Spatial distribution of preimaginal Bemisia tabaci (Homoptera: Aleyrodidae) in cotton and development of fixed-precision sequential sampling plans. Environ. Entomol. 23, 254-266.

Naranjo, S.E., Flint, H.M., 1995. Spatial distribution of adult Bemisia tabaci (Homoptera: Aleyrodidae) in cotton and development and validation of fixed-precision sampling plans for estimating population density. Environ. Entomol. 24, 261-270.

Naranjo, S.E., Ellsworth, P.C., Chu, C.C., Henneberry, T.J., 2002. Conservation of predatory arthropods in cotton: role of action thresholds for Bemisia tabaci. J. Econ. Entomol. 95, 682691.

Naranjo, S.E., Ellsworth, P.C., Chu, C.C., Henneberry, T.J., Riley, D.G., Watson, T.F., Nichols, R.L., 1998. Action thresholds for the management of Bemisia tabaci (Homoptera: Aleyrodidae) in cotton. J. Econ. Entomol. 91, 1415-1426.

Naranjo, S.E., Hagler, J.R., Ellsworth, P.C., 2003. Improved conservation of natural enemies with selective management systems for Bemisia tabaci in cotton. Biocontrol Sci. Technol. 13, 571-587.

Newsom, L.D., Smith, R.F., Whitcomb, W.H., 1976. Selective pesticides and selective use of pesticides. In: Huffaker, C., Messenger, P. (Eds.), Theory and Practice of Biological Control. Academic Press, New York, pp. 565-591.

Oliveira, M.R.V., Henneberry, T.J., Anderson, P., 2001. History, current status, and collaborative research projects for Bemisia tabaci. Crop Prot. 20, 709-723.

Palumbo, J.C., Horowitz, A.R., Prabhaker, N., 2001. Insecticidal control and resistance management for Bemisia tabaci. Crop Prot. 20, 739-765.

Peleg, B.A., 1988. Effect of a new phenoxy juvenile hormone analog on California red scale, Florida wax scale and the ectoparasite Aphytis holoxanthus. J. Econ. Entomol. 81, 88-92.

Pener, M.P., 2002. Insect growth regulators. In: Pimentel, D. (Ed.), Encyclopedia of Pest Management. Marcel Dekker, New York, pp. 398-401.

Rosenheim, J.A., Wilhoit, L.R., Armer, C.A., 1993. Influence of intraguild predation among generalist insect predators on the suppression of an herbivore population. Oecologia 96, 439-449.

Smith, K.M., Smith, D., Lisle, A.T., 1999. Effect of field-weathered residues of pyriproxyfen on the predatory coccinellids Chilocorus circumdatus and Cryptolaemus montrouzieri. Aust. J. Exp. Agric. 39, 995-1000.

Stern, V.M., Smith, R.F., van den Bosch, R., Hagen, K.S., 1959. The integrated control concept. Hilgardia 29, 81-101.

Tauber, M.J., Tauber, C.A., Daane, K.M., Hagen, K.S., 2000. Commercialization of predators: recent lessons from green lacewings (Neuroptera: Chrysopidae: Chrysoperla). Am. Entomol. 46, 26-38.

Ter Braak, C.J.F., Smilauer, P., 1998. CANOCO Reference Manual and User's Guide to Canoco for Windows: Software for Canonical Community Ordination (Version 4), Microcomputer Power, Ithaca, NY. 
van den Bosch, R., Hagen, K.S., 1966. Predaceous and parasitic arthropods in California cotton fields. California Agricultural Experiment Station 820, 32 pp.

van den Brink, P.J., Ter Braak, C.J.F., 1998. Multivariate analysis of stress in experimental ecosystems by Principal Response Curves and similarity analysis. Aqua. Ecol. 32, 163-178. van den Brink, P.J., Ter Braak, C.J.F., 1999. Principal response curves: analysis of time-dependent multivariate responses of biological communities to stress. Environ. Toxicol. Chem. 18, 138-148.

Whitcomb, W.H., Bell, K., 1964. Predaceous insects, spiders and mites of Arkansas cotton fields. Arkansas Agricultural Experiment Station Bulletin No. 690, 84 pp. 